\title{
Evaluating Methods to Estimate the Implied Cost of Equity Capital: A Simulation Study*
}

\author{
Holger Daske ${ }^{\dagger}$ Jörn van Halteren $\stackrel{\ddagger}{\ddagger}$ Ernst Maug§
}

December 14, 2010

\begin{abstract}
We evaluate accounting-based methods to estimate the implied cost of capital using a simulation approach. We simulate a model economy in which the true cost of capital is known and calibrate it to the CRSP-Compustat universe. We then compare the true cost of capital to the implied cost of capital estimates from ten different methods proposed in the literature in terms of bias, accuracy, and their correlation with the true cost of equity capital. Methods based on the residual income model perform better than those based on the abnormal earnings growth model. Methods that estimate the cost of capital and expected growth simultaneously work reasonably well if they rely on analyst forecasts instead of ex post realized values, even if analyst forecasts are biased. We suggest combined methods that are chosen so that the distortions from individual methods compensate each other and show that some simple combinations outperform all individual methods.
\end{abstract}

JEL classifications: C15, E37, M41

Keywords: Implied cost of capital, valuation, residual income, abnormal earnings growth, simulation

${ }^{*}$ We gratefully acknowledge financial support from the collaborative research center SFB TR 15 "Governance and the Efficiency of Economic Systems" and the Rudolph von Bennigsen-Foerderfoundation. We thank Inessa Love, The World Bank, for sharing her STATA code to estimate vector autoregressions using panel data sets. We also thank Alon Brav, Ingolf Dittmann, Günther Gebhardt, Eva Labro, Christian Leuz, Carsten Trenkler, and workshop participants at Maastricht University, the 2nd WHU Campus for Finance, the 3rd FARS Midyear Conference San Diego, the EAA Annual Congress Istanbul, and the DGF Annual Meeting Hamburg for helpful comments and advice.

${ }^{\dagger}$ University of Mannheim, 68131 Mannheim, Germany. E-mail: daske@bwl.uni-mannheim.de. Tel: +496211812280 .

${ }^{\ddagger}$ University of Mannheim, 68131 Mannheim, Germany. E-mail: halteren@bwl.uni-mannheim.de. Tel: +49621181 1964 .

$\S$ University of Mannheim, 68131 Mannheim, Germany. E-mail: maug@bwl.uni-mannheim.de. Tel: +496211811952 . 


\section{Introduction}

In this paper we evaluate accounting-based methods to estimate the implied cost of equity capital (ICC) using a simulation approach in which the true cost of capital is known. We show that ICC methods based on the residual income model perform better than those based on the abnormal earnings growth model. Combinations of several ICC methods outperform all individual methods if they average ICC estimates from firmlevel calculations with estimates that simultaneously calculate the cost of equity capital and expected growth for a portfolio of firms.

Previous work has addressed the same issue based on archival data (see Easton 2009, Chapter 8 for a review). This approach faces limitations because the true cost of equity capital is unobservable, so empirical research can only compare the cost of capital from ICC methods with (1) the cost of capital generated by an asset pricing model (Lee, Ng, and Swaminathan 2009), (2) its association with other firm-specific risk characteristics (Botosan and Plumlee 2005; Brav, Lehavy, and Michaely 2005), and (3) with realized stock returns (Guay, Kothari, and Shu 2005; Easton and Monahan 2005). The first approach encounters several well-known shortcomings outlined in the assetpricing literature (e.g., Elton 1999; Pastor and Stambaugh 1999; Fama and French 1997, 2002). The second approach requires that the selection of the risk factors considered is correct and exhaustive, which is unlikely (Easton and Monahan 2005). The third method is based on realized returns and therefore relies on very noisy estimates (e.g., Lundblad 2007; Pastor, Sinha, and Swaminathan 2008). In the light of these limitations, it may not seem surprising that the rankings and overall evaluation of the ICC methods differ significantly across studies. ${ }^{1}$

We perform Monte Carlo simulations of a suitably calibrated economy to address these shortcomings. Monte Carlo simulations are a well-established scientific approach, and they have been applied to address a range of questions in accounting and finance where important aspects of the underlying environment are unobservable so that tests of theories with real-world data are impossible. In simulations we observe these otherwise unknown variables by construction. ${ }^{2}$ The simulation model combines an econometric

\footnotetext{
${ }^{1}$ While research that focuses on the association of ICC methods with firm-specific risk characteristics concludes that some ICC approaches offer reliable estimates (Botosan and Plumlee 2005), research that focuses on the association with realized returns is skeptical on the reliability of any of these estimates (Guay, Kothari, and Shu 2005; Easton and Monahan 2005; Easton 2009). See also Botosan, Plumlee, and Wen (2010) for a more cautious conclusion.

${ }^{2}$ See e.g., Greenball (1968) for a classical example, and Labro and Vanhoucke (2007, 2008) for contemporary work. While Greenball's study is an example of studies in financial accounting eval-
} 
forecasting model, a business planning model, and a DCF-based valuation model. The model parameters are calibrated to the CRSP-Compustat universe. The valuation approach is designed so that it is neutral with respect to the specific assumptions of the ICC methods and therefore creates an appropriate benchmark for comparing and analyzing these methods.

In the next step of our analysis we use ten extant ICC methods that were proposed in the literature and calculate the cost of capital these methods generate for 20,000 firms from 100 industries in our simulated economy. ${ }^{3}$ We distinguish three broad groups of ICC methods: (1) residual income methods, which calculate the ICC individually for each firm; (2) abnormal earnings growth methods, which also determine the ICC at the firm level, and (3) industry-level methods, which estimate the cost of capital and expected growth simultaneously for a portfolio of firms. ${ }^{4}$ Finally, we compare the ICC from these methods with the true cost of capital, which is known for each firm in our simulated economy. The evaluation of the ICC methods follows Francis, Olsson, and Oswald (2000) and applies three criteria: (1) the bias of the method, which is particularly important for the correct estimation of the equity premium (e.g., Claus and Thomas 2001); (2) the accuracy of the method, which is significant for all practical applications of these methods, where correct firm-specific estimates of the cost of capital are required (e.g., company valuation, project appraisal); (3) the explainability of the method, which refers to the correlation between the ICC and the true cost of capital; this criterion is particularly important in research applications that require a proxy for the cost of capital.

Residual income methods have a small negative bias, whereas abnormal earnings growth methods have a larger and positive bias. Industry-level methods also tend to have a positive bias. Residual income methods tend to be the most accurate and industry-level methods that rely on analyst forecasts perform almost as well, even if

uating different accounting methods and measurement rules (Francis 1990; Rees and Sutcliffe 1993; Healy, Myers, and Howe 2002), the work of Labro and Vanhoucke is representative for the management accounting literature evaluating costing systems (Lambert and Larcker 1989; Balachandran, Balakrishnan, and Sivaramakrishnan 1997). Other prominent areas include evaluations of alternative testing procedures commonly used in accounting research (e.g., Barth and Kallapur 1996; Kothari, Sabino, and Zach 2005), detecting audit effectiveness (e.g., Knechel 1988), or detecting earnings management (e.g., Dechow, Sloan, and Sweeney 1995).

${ }^{3}$ We use the term model for a generic modeling framework, for example the residual income model or the dividend discount model. By contrast, we use the term method for specific methods that parameterize these models to determine the cost of capital and refer to them as ICC methods.

${ }^{4}$ We do not further divide industry-level methods, which could also be grouped into these two categories according to the valuation model they use. 
analyst forecasts are biased. Industry-level methods that rely on ex post realized values tend to be inaccurate, as do abnormal earnings growth methods. Residual income methods also have a higher R-squared in regressions of the ICC estimates on the true cost of capital, where most industry-level methods and all abnormal earnings growth methods tend to perform poorly. We attribute the generally poor performance of abnormal earnings growth methods compared to residual income methods to their modeling of future earnings. Whereas residual income methods model the level of future abnormal earnings, abnormal earnings growth methods model the changes in abnormal earnings, which seems to produce less reliable forecasts.

All methods provide distorted estimates of the cost of capital, even if the average bias is small. Firm-level methods overestimate the cost of capital if the true cost of capital is high, and underestimate the cost of capital if the true cost of capital is low. By contrast, most industry-level methods generate the opposite result. We trace this distortion to the modeling of cash flow patterns by the ICC methods by applying the concept of equity duration developed in Dechow, Sloan, and Soliman (2004) and call it the duration effect. Thus, our study contributes by adding this effect to the theoretical discussions on ICC methods in the literature (e.g., Hughes, Liu, and Liu 2009; Lambert 2009; Pastor, Sinha, and Swaminathan 2008).

Finally, we investigate the possibility that combinations of ICC methods may perform better than individual methods. ${ }^{5}$ The analysis suggests that firm-level methods have a lower accuracy because they systematically overestimate the true cost of capital when it is high and vice versa, whereas industry-level methods do the opposite. Combining methods from each category should therefore lead to better estimates because the errors of the individual methods compensate each other. We find that this is indeed the case and we highlight two methods that combine two, respectively four, individual methods and show that they tend to outperform all individual methods as well as prior ad hoc combinations. In particular, the combination of equally weighted estimates from Gebhardt, Lee, and Swaminathan (2001) and Easton, Taylor, Shroff, and Sougiannis (2002) provide a useful trade-off between simplicity and the ability to capture the true cost of equity capital in most circumstances. We conclude the paper with a number of robustness checks that highlight various aspects of our simulation model and the valuation approach. Our main conclusions are robust to changing details of our research design.

\footnotetext{
${ }^{5}$ The general argument for combinations is based on Hail and Leuz (2006, 2009) and Dhaliwal, Krull, and Li (2007).
} 
A number of papers address the shortcomings of ICC methods or suggest improvements of existing methods. One area of improvements is the replacement of analyst forecasts with realized values (Easton and Sommers 2007; O'Hanlon and Steele 2000) or with a statistical forecasting model (Hou, Van Dijk, and Zhang 2010). These analyses are complementary to ours because we derive the properties of ICC methods in a context in which unbiased forecasts are already available. Botosan and Plumlee (2005) and Easton and Monahan (2005) use different methodologies based on empirical data that reveal some shortcomings of existing ICC methods. By contrast, our simulation approach opens the black box, analyzes the structure of ICC methods and derives diagnostics in an environment where the true cost of equity capital is known. On this basis we can identify the errors that are systematically built into specific methods and can then suggest combinations of methods that benefit from compensating errors. Ours is not only the first study to evaluate industry-level ICC methods, but also contributes by showing how their specific properties add to the construction of combined methods.

The remainder of this paper is structured as follows. The following Section 2 develops the simulation approach for our model economy. We discuss the different ICC methods and how we implement them in Section 3. Section 4 contains the main analysis. In Section 5 we evaluate how the individual methods may be combined. Section 6 presents robustness checks and Section 7 concludes with a discussion of the limitations of our approach and suggestions for future research.

\section{Methodology: Simulating a model economy}

We conduct our simulation by setting up a business planning model, where we forecast a complete set of financial statements (i.e. income statement, balance sheet, and statement of cash flows) for an economy of 20,000 firms for 50 years. ${ }^{6}$ We calibrate the parameters of our model to those of a large sample of U.S. firms. As common in financial modeling and corporate valuation, we use sales growth and profitability (EBITDA-margin) as our main value drivers ("percentage-of-sales model"). ${ }^{7}$ We empirically estimate the parameters that describe the joint time series of these two variables. Sales growth rates and EBITDA-margins are then the random variables in our Monte Carlo simulation from which all other accounting and cash flow items in the projected

\footnotetext{
${ }^{6}$ All calculations for this Monte Carlo simulations are implemented using MATLAB.

${ }^{7}$ We use a simplified textbook approach, see, for example, Lundholm and Sloan (2007) or Penman (2009).
} 
financial statements are calculated, mostly as percentages of sales. In the final step, we draw each firm's cost of capital from a distribution and calculate the value of this firm in our simulated economy by discounting its future expected cash flows at this rate. Thus, we obtain for each firm in our simulation a complete set of financial statements, a cost of capital, realized and expected future cash flows and earnings, and an associated firm value.

The empirical basis for calibrating our model rests on an unbalanced panel of firms from 1970 to 2009, which we obtain from the CRSP-Compustat Merged data file. We only use non-financial firms listed on the NYSE, AMEX, or NASDAQ. We derive balance sheet and income statement items from the Compustat files, while returns, dividends, and market capitalization are obtained from CRSP. We are left with a sample of 96,719 firm-year observations for 8,036 firms. The median firm-year in our sample has sales of $\$ 170.2$ million, total assets of $\$ 154.9$ million, and a market capitalization of $\$ 143.28$ million (these numbers are not tabulated).

\section{[Insert Table 1 about here.]}

Table 1 summarizes the salient financial ratios for our sample and the model parameters we use for our simulation. We typically use the median of the distribution of a ratio and round the model parameters (e.g., the median ratio of property, plant and equipment to sales is $21.5 \%$, but we use $20 \%$ ). We deviate from the median firm in some instances (e.g., the plowback rate) in order to achieve a better overall calibration, particularly of the valuation ratios (PE ratio and market-to-book ratio). We provide the reason for these decisions and an assessment of the quality of our calibrations below and later perform robustness checks to show that our modeling choices are inconsequential for our main results.

\subsection{Forecasting sales growth and EBITDA-margins}

Vector autoregressions. We model a firm's sales growth and EBITDA margins as a first-order vector autoregressive process $(\operatorname{VAR}(1)) .{ }^{8}$ Unlike a univariate autoregressive (AR) model, vector autoregressions also model the cross-dependence of margins on sales growth and vice versa and therefore model also the dynamic behavior of the correlation between these key value drivers. Denote the rate of sales growth in period $t$

\footnotetext{
${ }^{8}$ For a review of vector autoregressive models, see Brooks (2008). We follow the approach used in Love and Zicchino (2006) or Dorn, Huberman, and Sengmueller (2008).
} 
(i.e., Sales $_{t} /$ Sales $_{t-1}-1$ ) for firm $i$ by $g_{i, t}^{S}$ and the EBITDA margin (henceforth simply: margin) by $m_{i, t}$. We then estimate the following model: ${ }^{9}$

$$
\begin{aligned}
& g_{i, t}^{S}=\alpha_{0, i}+\alpha_{g} g_{i, t-1}^{S}+\alpha_{m} m_{i, t-1}+\varepsilon_{i, t} \\
& m_{i, t}=\gamma_{0, i}+\gamma_{g} g_{i, t-1}^{S}+\gamma_{m} m_{i, t-1}+\eta_{i, t}
\end{aligned}
$$

We run the vector autoregression from (1) and (2) on our sample using panel VAR regression analysis. We winsorize the data for sales growth and EBITDA margins at the $1 \%$ level to reduce the impact of extreme outliers.

[Insert Table 2 about here.]

Panel A of Table 2 reports the results for the panel vector autoregression of sales growth and EBITDA margins. Shocks to margins exhibit some persistence $\left(\gamma_{m}=\right.$ 0.596), whereas the impact of sales growth on past sales growth is rather weak $\left(\alpha_{g}=\right.$ 0.166). There is an economically meaningful and negative impact of past margins on sales growth $\left(\alpha_{m}=-0.166\right)$. Also, there is a significant positive correlation of 0.354 between the contemporaneous shocks to margins $\eta_{i, t}$ and to cash flows $\varepsilon_{i, t}$ (panel B). We would miss these effects with univariate autoregressions. By contrast, the impact of past sales on profitability is statistically insignificant $\left(\gamma_{g}=-0.004\right)$.

Our first-order VAR framework with two variables strikes a balance between simplicity and realism. We also experimented with second-order VAR processes, but found that second-order lags in equations (1) and (2) are only marginally significant and generate virtually identical impulse response functions. The key feature of the processes modeled here is the persistence of shocks, i.e., the length of time for which a shock to margins or sales growth has an impact on each of the value drivers. Whether the model captures the dynamic evolution of the value drivers more closely seems immaterial for valuation.

Simulations. In our Monte Carlo simulation, we generate 200 industries of 100 firms each, and for each industry we generate values for sales growth and margins from the processes (1) and (2). If $t=0$ marks the beginning of our business planning model, then

\footnotetext{
${ }^{9}$ In fact, we estimate this model after first demeaning (subtracting the time-series mean for each variable and for each firm) and then applying a so-called Helmert transformation (see Arellano and Bover 1995, pp. 41-43, for details). As a result, we do not obtain and therefore do not report intercepts or R-squareds.
} 
we start the processes at $t=-4$ because for some applications we need information about prior periods, and we end the process at $t=1$ to obtain realized values for those methods that use ex post realizations. ${ }^{10}$ We do not simulate values for periods later than $t=1$ because for later periods we only need expected values. Expected values are always generated for 50 periods. We use the parameters from panels A and B of Table 2 with two modifications.

First, we draw the beginning values at $t=-4$ for sales growth and for the margin from normal distributions. The distribution of the beginning value for sales growth has a mean of $6.0 \%$ and a standard deviation of $20.0 \%$. The median in the data from Table 1 is $10.6 \%$ for sales growth and $19.9 \%$ for the time-series standard deviation of sales growth. The mean sales growth rate of $6 \%$ in the simulations differs from the median growth rate of $10.6 \%$ in our sample (see Table 1), because we obtain better approximations for our valuation ratios for reasons we develop further below. Note that only the time-series variation and not the cross-sectional variation is relevant for calibrating the time series processes (1) and (2). The mean for the beginning value of the margin is $12 \%$ with a standard deviation of $5.0 \%$, where the empirical values from Table 1 are $11.4 \%$ and $4.7 \%$, respectively. We apply the same standard deviations to the residuals $\varepsilon_{i, t}$ and $\eta_{i, t}$ in (1) and (2) as we use for the initial values. We model these using a joint distribution based on the empirical correlation of 0.354 .

Second, we do not obtain estimates for the intercept coefficients $\alpha_{0}$ and $\gamma_{0}$ from the panel VARs (see also footnote 9). Instead, we set these coefficients so that the longterm values for sales growth and the margin from processes (1) and (2) converge to firm-specific long-term values and report the average values in panel $\mathrm{C}$ of Table 2 . We draw long-term sales growth for each firm from a truncated normal distribution with a mean of $6 \%$ and a standard deviation of $2 \%$. Similarly, long-term margins are drawn from a truncated normal distribution with a mean of $12 \%$ and a standard deviation of $1 \%$. In both cases, the distribution is truncated to values within two standard deviations of the mean. Drawing long-term growth rates and margins from a distribution allows us to differentiate between different types of firms, particularly growth stocks and value stocks. We obtain the intercepts $\alpha_{0, i}$ and $\gamma_{0, i}$ for our simulations by substituting $\varepsilon_{i, t}=0$, $\eta_{i, t}=0$, and the firm-specific values for long-term sales growth and the long-term margin into equations (1) and (2) and then solving for the intercept values. For the average

\footnotetext{
${ }^{10}$ The model by Gebhardt, Lee, and Swaminathan (2001) requires information about prior periods in order to calculate industry averages for the return on equity. Easton and Sommers (2007) use realizations of period $t=1$.
} 
across the firm-specific intercepts we obtain $\alpha_{0}=0.070$ and $\gamma_{0}=0.049$.

Figure 1 presents the impulse response functions of sales growth and margins for the first 10 periods in response to a single positive, one standard deviation shock to growth (panel A) and a one standard deviation shock to the margin (panel B). We see that the processes converge relatively fast and are close to their original values after about 4 to 6 periods after the arrival of the shock if no further shocks arrive. Shocks to margins are more persistent, whereas shocks to growth have no impact on the margin.

\section{Figure 1: Impulse response functions}

This figure plots the impulse response function for the sales growth and margin equations (1) and (2). The left figure shows the reactions of sales growth and margins from a one standard deviation shock $(20 \%)$ to the growth rate in $t=0$. The right figure highlights the reactions for a one standard deviation shock $(5 \%)$ to the margin in $t=0$.
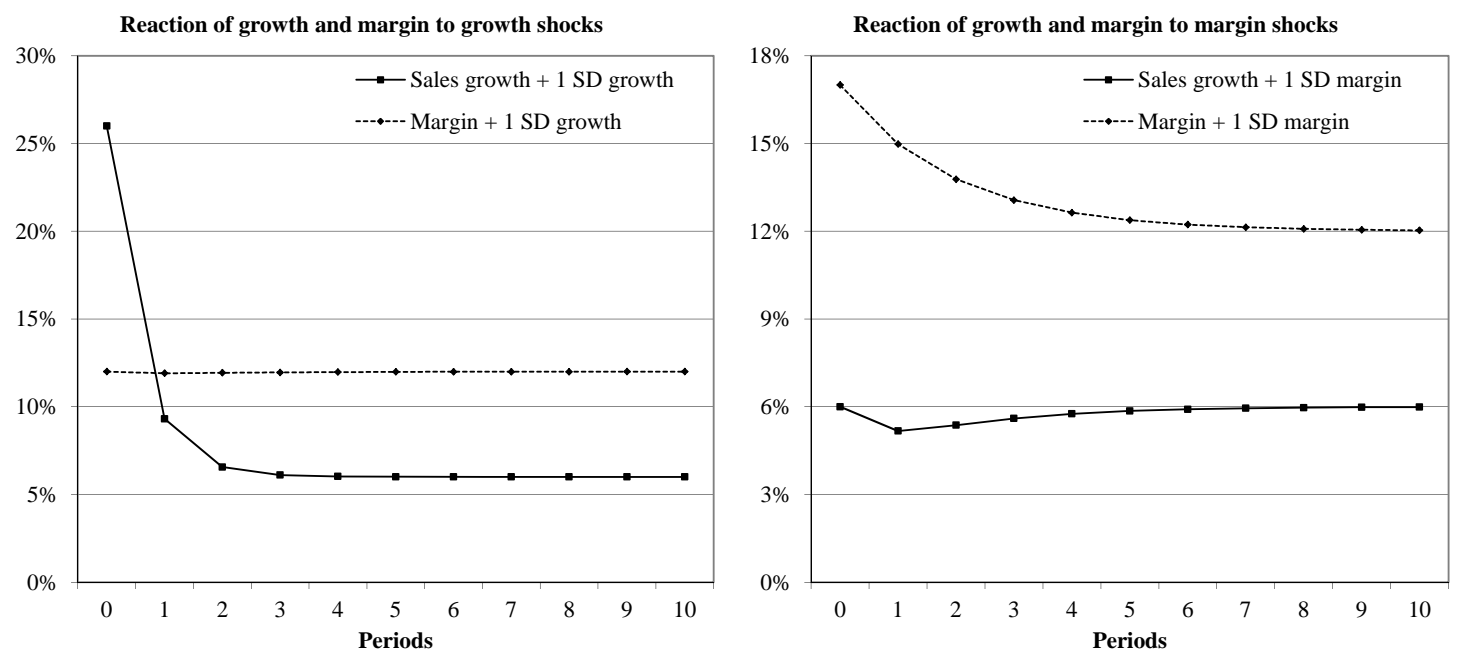

Forecasting and expectations. For calculating firm values and for implementing the ICC methods, we have to generate market expectations as well as analyst forecasts about future earnings and cash flows. We generate forecasts for each firm from our VAR-estimates by first inserting the beginning values of margin and sales growth as well as the estimates for the coefficients in (1) and (2) to obtain expected sales growth and margins in period $t=1$. We then use these forecasts iteratively to obtain forecasts for period $t=2$ and repeat the exercise to estimate forecasts for all periods within the detailed planning horizon of 50 periods in our baseline simulation.

Our baseline approach assumes rational expectations. In particular, we assume that the forecasts of investors in the stock market and analyst forecasts are the same, 
and that both of them use the correct model of the economy when valuing the firm. This assumption is potentially a strong one because analyst forecast bias is a widelydocumented phenomenon (e.g., Brown 1993; Easton and Sommers 2007). We therefore include a robustness check where we allow for optimism on the part of analysts.

Terminal values. For the terminal value after the detailed planning horizon we model terminal sales growth denoted by $g_{i, T}$ as a truncated normal random variable that varies for each firm on the interval $[-3 \% ;+3 \%]$ with a mean of $0 \%$ and a standard deviation of $1 \%$. Hence terminal growth is equal to zero on average, but not equal to zero for every firm. We later check for the impact of our terminal value assumptions by shortening or extending the detailed planning period.

\subsection{Generating company values from a business planning model}

Income statements. We denote expectations for sales growth and margins from our forecasting model with $\hat{g}_{i, t}^{S}=E\left(g_{i, t}^{S}\right)$ and $\hat{m}_{i, t}=E\left(m_{i, t}\right)$, respectively. Based on these forecasts, we can then calculate expected sales and EBITDA from:

$$
\begin{gathered}
S_{i, t}=\left(1+\hat{g}_{i, t}^{S}\right) S_{i, t-1}, \\
\text { EBITD } A_{i, t}=\hat{m}_{i, t} \times S_{i, t} .
\end{gathered}
$$

We set initial sales $S_{0}$ to 100 . We calculate depreciation as a percentage of sales and deduct it from EBITDA to obtain EBIT, and then deduct taxes at a rate of $35 \%$ of EBIT (if EBIT is positive) to obtain bottom-line net income. ${ }^{11}$ Finally, retained earnings are equal to the plowback rate times net income; the remaining earnings are distributed as dividends. The plowback rate $p b$ varies for each firm according to a truncated normal distribution on the interval $[0.2 ; 0.8]$ with mean equal 0.5 and a standard deviation of 0.1 .

Balance sheets. We construct a highly simplified balance sheet that consists only of cash, current assets ( $c a$ ) and property plant, and equipment (ppe) on the assets side, and current liabilities $(\mathrm{cl})$ and shareholders' equity (book value of equity, $b v$ ) on the liabilities and equity side. Hence, we assume that firms are fully equity financed and abstract from debt financing. Including interest-paying debt would require modeling the cost

\footnotetext{
${ }^{11}$ We do not account for tax-loss carry-forwards or carry-backs.
} 
of debt, debt issues, and the possibility of bankruptcy over time and would produce significantly more complexities without generating additional results. We therefore include only current liabilities.

Current assets, net PPE, and current liabilities are all calculated as percentages of contemporaneous sales using the ratios from Table 1 . The book value of equity $b v_{t}$ always obeys the clean surplus condition:

$$
b v_{t}=b v_{t-1}+e_{t}-d_{t}
$$

where $e_{t}$ denotes total earnings (net income) and $d_{t}$ denotes total dividends. Cash is the plug variable and therefore calculated as:

$$
\operatorname{cash}_{t}=c l_{t}+b v_{t}-p p e_{t}-c a_{t} .
$$

Steady-state behavior. The assumptions about the model parameters, in particular the percentage-of-sales ratios, have direct implications for the long-term behavior of our business planning model. For each firm, each financial ratio converges to some steadystate value. In the appendix we show that the return on equity converges to (denote long-term steady state values by upper bars):

$$
\overline{r o e}=\frac{\bar{g}_{i}^{S}}{p b} .
$$

In our model, the return on equity therefore results from the assumptions about the plowback ratio and the long-term growth rate. In the appendix we also show that the equity-sales ratio $b v_{t} / S_{t}$ converges to:

$$
\overline{\left(\frac{b v}{S}\right)}=\frac{\left(1+\bar{g}_{i}^{S}\right)(m-d)(1-T) p b}{\bar{g}_{i}^{S}} .
$$

Given our baseline model parameters, the steady-state value of the equity-to-sales ratio from (8) equals 0.402 for the typical simulated firm, which has a plowback rate of 0.5 , a long-term growth rate of $6 \%$, and a long-term margin of $12 \%$.

We calibrate the model so that the typical simulated firm is in a steady state, so that for this firm all financial ratios, including the ROE and the equity-sales ratio, start out in the steady state. We therefore set the initial book value $b v_{0}$ to 40 , i.e., to $40 \%$ of initial sales. For the typical simulated firm we also obtain a steady-state value of $12 \%$ 
for the ROE from (7), which is equal to its starting value. However, given that the true cost of capital as well as the expected growth rates are stochastic, it is only the median firm that is in a steady state. Firms with higher growth have a higher ROE from (7) and converge to a lower equity-to-sales ratio from (8) and vice versa for low-growth firms.

Statements of cash flows. We obtain free cash flows $\left(f c f_{t}\right)$ from earnings by adding back depreciation $\left(d e p_{t}\right)$ and subtracting investments in working capital and capital expenditures (changes in net PPE):

$$
\begin{aligned}
f c f_{t} & =e_{t}+\operatorname{dep}_{t}-\Delta \text { Working capital }-\Delta \text { Net PPE } \\
& =e_{t}+\operatorname{dep}_{t}-\left(c a_{t}-c l_{t}-\left(c a_{t-1}-c l_{t-1}\right)\right)-\left(p p e_{t}-p p e_{t-1}+\operatorname{dep}_{t}\right) .
\end{aligned}
$$

Cost of capital. We draw the cost of capital from a distribution that allows us to evaluate firm-level methods as well as industry-level ICC methods and that is also consistent with the notion that growth stocks have a lower cost of capital than value stocks, thus capture the insight that the CoEC are not independent from the cash flow risks of the firm (e.g. Beaver, Kettler, and Scholes 1970). More specifically, the cost of equity capital $r_{E, i}$ of firm $i$ are given by

$$
r_{E, i}=r_{E, I n d}+a\left(\bar{g}_{i}^{S}-\bar{g}\right)+\varepsilon_{i}
$$

where $r_{E, I n d}$ is the cost of equity capital (CoEC) of firm $i$ 's industry and $\left(\bar{g}_{i}^{S}-\bar{g}\right)$ is the deviation of firm $i$ 's long-term growth rate from the overall mean of $6 \%$. We draw the industry cost of capital from a normal distribution with a mean of $10 \%$ and a standard deviation of $4 \% .{ }^{12}$ The distribution is winsorized at the risk-free rate $r_{f}$ of $4.5 \%$. Then we draw the firm-specific component $\varepsilon_{i}$ of the CoEC from a distribution with a mean of zero and a standard deviation of $1 \%$. Finally, we set $a=-0.5$, which generates a difference in mean expected equity returns between the highest book-to-market decile and the lowest book-to-market decile of $10.4 \%$ and introduces a link between cash flow shocks and shocks to expected returns. Fama and French (1992) find return differences between the highest and lowest book-to-market decile of around 16.7\%, while Lettau and

\footnotetext{
${ }^{12}$ Easton and Monahan (2005), Table 2, report cost of equity capital in a range from $8.8 \%$ to $12.9 \%$, depending on the ICC method used. Other studies comparing ICC methods report only average risk premia over time, and thus do not provide a suitable direct benchmark. Dechow, Sloan, and Soliman (2004) use $r_{E}=12 \%$ to calibrate their model.
} 
Wachter (2007) document a difference of only 4.9\%. ${ }^{13}$ We therefore use an intermediate value in our simulation. With these parameters, the overall standard deviation of the cost of capital in our economy is therefore $\sqrt{0.04^{2}+0.01^{2}+(-0.5)^{2} 0.02^{2}}=0.042$.

Research has identified a range of factors other than the book-to-market ratio and the value versus growth distinction that also affect the cost of capital, some for reasons that are not yet fully understood. Prominent examples are firm size, stock market liquidity, and disclosure quality. ${ }^{14}$ We abstract from these variables, which are outside of our modeling framework. In many ways we see this aspect as an advantage of our more clinical approach. The features of the ICC methods that emerge from the simple model economy would in all likelihood also carry over to a more realistic model that would feature these additional effects. Similarly, we draw only one CoEC for each firm and assume that these CoEC do not change over time and are known to investors. The effects analyzed by Hughes, Liu, and Liu (2009) are therefore absent from our model.

Equity values. We construct forecasts for all free cash flows as explained above and then calculate the market value of the equity of each firm $i$ using the firms' drawn cost of capital and a standard DCF-approach (e.g., Lundholm and Sloan 2007; Penman 2009). We denote these simulated firm values generated by the model by $P_{0}^{D G P}$, where DGP stands for "data generating process":

$$
P_{i, 0}^{D G P}=\sum_{t=1}^{50} \frac{E_{0}\left(f c f_{i, t}\right)}{\left(1+r_{E, i}\right)^{t}}+\frac{E_{0}\left(f c f_{i, 50}\right)\left(1+g_{i, T}\right)}{\left(r_{E, i}-g_{i, T}\right)\left(1+r_{E, i}\right)^{50}}
$$

Our results are robust if we use the dividend discount model instead of the DCF model (11) to generate firm values.

\subsection{Comparison of the simulated economy to real data}

We generate 200 industries of 100 firms each using the design described in the previous two sections. For 11 out of 20,000 firms (0.1\%) the market value of equity is smaller than or equal to zero. ${ }^{15}$ We classify these firms as bankrupt and remove them from

\footnotetext{
${ }^{13}$ See Fama and French (1992), Table 4, which computes a difference of $1.4 \%$ for monthly returns, and Lettau and Wachter (2007), Table 1.

${ }^{14}$ See Hail and Leuz (2006) for a comprehensive set of factors that influence the CoEC empirically.

${ }^{15}$ This may happen for firms with negative current margins in combination with high cost of capital. The negative margins generate negative free cash flows in the current periods. Later long-term positive free cash flows sometimes do not suffice to outweigh the earlier negative free cash flows if the discount
} 
further analyses.

[Insert Table 3 about here.]

Table 3 compares the simulated values with the archival data in Table 1 for key financial ratios. For each ratio, we calculate the difference between the quantiles for the simulated distribution and the respective quantile for the empirical distribution. We approximate the medians for sales growth, EBITDA-margin, the market-to-book ratio, and the PE-ratio very well. The market-to-book ratio is lower by 0.20 and the PE ratio is lower by 0.93 compared to the Compustat sample. The median return on assets is $2.21 \%$ higher in the simulations than the corresponding figure in our sample, whereas the median return on equity is higher in the simulations by $0.08 \%$. Since we do not model leverage, we can only calibrate one profitability ratio and therefore choose to calibrate the return on equity, which is more relevant for the valuation models. Overall, we have slightly lower valuation ratios and a higher profitability in our simulated economy relative to the empirical sample. We use a plowback rate of only $50 \%$ because a higher rate leads to large book equity values and correspondingly lower market-to-book ratios. The median plowback rate of firm-years in which cash is distributed is $65 \%$ in our empirical sample (see Table 1). We show later that this decision is inconsequential for our results. Sales growth differs significantly from the empirical data because we obtain better calibrations with a rate of $6 \%$. This choice is realistic for two reasons. First, the empirical sample suffers from survivorship bias and under represents firms with low growth rates, especially bankrupt firms. Second, growth in profits and growth in margins are closely linked in our model, but not in the data where firms also grow through zero-NPV projects like acquisitions that add to sales growth but much less to value growth.

We match the tail behavior of the empirical distribution not as accurately as the median. These differences between the simulation and our sample come from a number of simplifications. We use normal distributions throughout, whereas the distributions of the data are skewed and have tails that are different from those of the normal distribution (compare means and medians for key ratios in Table 1). Also, we model only the correlation between sales growth and margin in our VAR-estimations, but ignore correlations between other financial ratios. Finally, our simulations generate values based on a typical firm with key parameters (terminal growth, plowback rate) rate is high, which then leads to market values below zero. 
perturbed by random variables. Moreover, the medians in Table 1 do not correspond to a typical firm, since the median of each parameter corresponds to a different firm.

In summary, our simulated values are more symmetric and more concentrated around the mean than our empirical sample. To some extent these differences are a cost we incur for the simplifications we make in our simulation. The corresponding benefit is that we do not need to winsorize or truncate to eliminate outliers, approaches commonly employed in empirical studies. Also, the results of our study are more representative for a typical firm. We run several robustness checks on our key modeling assumptions and show that our key results are not sensitive to the particular parameter values chosen here.

\section{Implied Cost of Capital Methods}

In this section we develop the ten different Implied Cost of Capital (ICC) methods we compare in our subsequent analysis. The starting point of all these methods is the dividend discount model (DDM), which values the equity of a firm as:

$$
P_{0}=\sum_{t=1}^{t=\infty} \frac{d_{t}}{\left(1+r_{E}\right)^{t}}
$$

Assuming Modigliani and Miller (1961) dividend irrelevance, the dividend discount model (12) and the DCF model (11) generate the same equity value $P_{0} \cdot{ }^{16}$ We distinguish between three groups of methods, all of which can be derived from the DDM: (1) two firm-level methods based on the residual income model, which includes Claus and Thomas (2001) and Gebhardt, Lee, and Swaminathan (2001); (2) four firm-level methods based on the abnormal earnings growth model (AEG model), which includes Gode and Mohanram (2003) and a number of methods based on capitalization ratios, which are discussed in Easton (2004); (3) four industry-level methods, which rely also on either the residual income model or on the AEG model, but estimate the cost of equity capital at the industry-level rather than at the firm level and simultaneously infer a long-term growth rate. Table 4 summarizes the key characteristics of these

\footnotetext{
${ }^{16}$ Note that our simulation model does not assume dividend irrelevance. In the model, retained earnings generate a return that is determined by the profitability implied by the EBITDA-process, which generally differs from the cost of equity of the firm.
} 
methods. ${ }^{17}$ For all models we keep very closely to the assumptions in the respective original articles.

\section{[Insert Table 4 about here.]}

Residual income methods. The generic equation of the residual income model can be written as:

$$
P_{0}=b v_{0}+\sum_{t=1}^{T} \frac{a e_{t}}{\left(1+r_{E}\right)^{t}}+\frac{a e_{T+1}}{\left(r_{E}-g_{a e}\right)\left(1+r_{E}\right)^{T}},
$$

where $a e_{t}$ denotes residual income or abnormal earnings (we use both terms interchangeably) at time $t$ and $g_{a e}$ is the long-term growth of residual income. We implement the method of Claus and Thomas (2001) (henceforth CT) by using $T=5$ and $g_{a e}=r_{f}-3 \%=1.5 \%$, since we assume $r_{f}=4.5 \%$ throughout. CT use analyst forecasts for expected future earnings for the first five periods, whereas we use the forecasts of earnings from the time-series forecasts and our business planning model. As in CT, the book equity forecasts are obtained assuming a plow-back rate of $50 \%$. The ICC is then obtained as an internal rate of return from (13).

We implement the method of Gebhardt, Lee, and Swaminathan (2001) (GLS) with $T=12$ and $g_{a e}=0$. Furthermore, we can rewrite $a e_{t}=\left(\right.$ roe $\left._{t}-r_{E}\right) b v_{t-1}$, where roe $_{t}$ is the book return on equity. For the first three periods we use the explicit forecasts from our forecasting model. From $t=3$ to $t=12$ we use a linear interpolation between roe $_{3}$ and the industry median roe over all firms in the same industry during the last 5 years (periods $t=-4$ to $t=0$, see above), where we exclude all firm-year observations of firms with negative net income.

We obtain the book equity forecasts for GLS using an endogenous payout ratio, which equals the current realized payout ratio if net income is positive; otherwise the payout ratio equals current dividends divided by $6 \%$ of total assets. Also, if the estimated payout ratio is larger than 1 or smaller than 0 , the ratio is set equal the respective boundary values. The ICC is again obtained as an IRR from (13).

\footnotetext{
${ }^{17}$ Easton (2009) provides a comprehensive survey of these methods. See also Table 1 in Easton and Monahan (2005).
} 
Abnormal earnings growth (AEG) methods. The AEG model rests on the definition of abnormal earnings growth $\Delta a e_{t} \equiv a e_{t}-a e_{t-1}$ :

$$
\begin{aligned}
\Delta a e_{t} & =\Delta e_{t}-r_{E}\left(e_{t-1}-d_{t-1}\right) \\
& =\Delta e_{t}-r_{E} \Delta b v_{t-1},
\end{aligned}
$$

where the second line assumes the clean surplus condition. Note that the AEG model does not generally assume clean surplus, but this condition always holds in our business planning model. With the clean surplus condition imposed, the residual income model and the AEG model are isomorphic. The generic valuation equation for the AEG model is:

$$
P_{0}=\frac{1}{r_{e}}\left[e_{1}+\sum_{t=1}^{T-1} \frac{\Delta a e_{t+1}}{\left(1+r_{E}\right)^{t}}+\frac{\Delta a e_{T+1}}{\left(1+r_{E}\right)^{T-1}\left(r_{E}-g_{a e g}\right)}\right],
$$

which decomposes the value of equity into capitalized earnings and future earnings growth (see also Ohlson and Gao 2006).

Gode and Mohanram (2003) (GM) use $T=1$ (so the middle term in (15) drops out). Then:

$$
P_{0}=\frac{e_{1}}{r_{e}}+\frac{\Delta a e_{2}}{r_{e}\left(r_{e}-g_{a e g}\right)},
$$

which can be rewritten as a quadratic equation. We obtain the CoEC as the larger square root of this quadratic equation. GM set $g_{a e g}=r_{f}-3 \%$. Dividend forecasts are obtained using the same procedure as for the GLS method. ${ }^{18}$

Easton (2004) uses $g_{\text {aeg }}=0$, so that (16) simplifies to:

$$
P_{0}=\frac{\Delta e_{2}+r_{E} d_{1}}{r_{E}^{2}}
$$

The CoEC is then obtained as $r_{E}=\sqrt{1 / \mathrm{MPEG}}$, where MPEG denotes the modified PEG ratio: $\mathrm{MPEG}=P_{0} /\left(\Delta e_{2}+r_{E} d_{1}\right)$. Similarly, with the additional assumption $d_{1}=0$ and the definition PEG $=P_{0} / \Delta e_{2}$, Easton (2004) obtains the CoEC as $r_{E}=\sqrt{1 / \mathrm{PEG}}$. Note that by construction, MPEG < PEG so that the MPEG ratio leads to a higher estimate of the cost of capital than the PEG ratio if dividends are positive. Finally, if we assume also that $\Delta a e_{t}=0$ for all $t \geq 2$, then (16) simplifies to $P_{0}=e_{1} / r_{E}$, so that $r_{E}=1 / \mathrm{PE}$. We implement all four applications of the AEG model in the same way,

\footnotetext{
${ }^{18}$ Note that GM use the average of the two year growth and the $\mathrm{I} / \mathrm{B} / \mathrm{E} / \mathrm{S}$ growth rate to avoid losing observations. We use the model in the original form in (16).
} 
by using forecasts of dividends, earnings, and book values from our business planning model and then inferring the cost of capital according to the formulae above. Like Easton (2004) we set $d_{1}=d_{0}$ and apply the MPEG method only to firms where $\Delta e_{2} \geq 0$. Note from (17) that this assumption imposes a stricter condition than necessary.

Industry-level methods. Industry-level methods infer the cost of capital and the growth rate simultaneously by rewriting the perpetual version of a valuation model so that it resembles a linear regression equation. We describe the approach of Easton (2004) as an example. He uses the two-period AEG model and rearranges (16) to obtain:

$$
\frac{e_{2}+r_{E} d_{1}}{V_{0}}=r_{E}\left(r_{E}-g_{a e g}\right)+\left(1+g_{a e g}\right) \frac{e_{1}}{P_{0}}
$$

We run a linear regression of $\frac{e_{2}+r_{E} d_{1}}{V_{0}}$ on the forward earnings-to-price ratio $e_{1} / P_{0}$ for all firms in the same industry. We begin by assuming a starting value of $12 \%$ for $r_{E}$ and then recover one cost of capital estimate and one implied growth rate for each industry from the regression coefficients in (18). We recalculate the dependent variable $\frac{e_{2}+r_{E} d_{1}}{V_{0}}$ with the values obtained and then iterate regression (18) until the estimates of the cost of equity capital and of the implied growth rate converge. ${ }^{19}$

The other portfolio approaches follow a similar logic. O'Hanlon and Steele (2000) use the residual income equation (13) with $T=1$ (hence, the middle term in (13) drops out) and obtain a regression equation with the realized book return on equity roe $_{1}$ as the dependent variable. Accordingly, we implement their regression approach and use realized instead of forecasted earnings to calculate roe $_{1}$.

Easton, Taylor, Shroff, and Sougiannis (2002) (ETSS) start with the two-stage formulation of the residual income model (13) with $T=4$ and obtain a formulation similar to that of O'Hanlon and Steele after aggregating earnings and dividends for the first four years. We implement ETSS by running a linear regression of their measure of fourperiod cum-dividend earnings, scaled by the book value of equity, on the price-to-book ratio $P_{0} / b v_{0}$ for all firms in the same industry.

Easton and Sommers (2007) also start from the perpetual version of the residual income formula, but then assume that perpetual growth $g_{a e}$ starts at $t=0$. They therefore obtain a regression equation in terms of roe $e_{0}$ instead of roe $_{1}$. With this modification the implementation of their approach is similar to that of O'Hanlon and

\footnotetext{
${ }^{19}$ Convergence is achieved if both the change in the growth rate and the change in the cost of capital between two iterations is smaller than $10^{-10}$.
} 
Steele (2000).

\section{Analysis}

We start our analysis by comparing the ten individual methods for estimating the implied cost of capital. We follow Francis, Olsson, and Oswald (2000) and evaluate each method primarily in terms of its bias, accuracy, and explainability, where the latter refers to the correlation between the implied cost of capital and the true cost of capital. The importance of each of these criteria depends on the application, which we outline in the Introduction and discuss further in the Conclusion. We discuss the bias, accuracy, and feasibility in the next section 4.1 and defer the more involved analysis of explainability to Section 4.2 .

\subsection{Bias, accuracy, and feasibility}

The starting point for each criterion is the difference $\delta_{i}^{M} \equiv r_{E, i}^{M}-r_{E, i}$ between the implied cost of capital $r_{E, i}^{M}$ estimated by method $M$ and the true cost of capital $r_{E, i}$. Table 5 reports the results for bias and accuracy.

[Insert Table 5 about here.]

Bias. Bias is defined as the sample mean or median of $\delta_{i}^{M}$. For all methods except GM and the MPEG ratio the mean and the median bias is below $2 \%$ in absolute value, which seems acceptably small. The residual income methods (CT and GLS) both slightly underestimate the cost of capital and have the lowest bias in absolute value. Three of the four methods based on the abnormal earnings growth model (GM, PEG ratio, MPEG ratio) overestimate the cost of capital, and the AEG methods have on average the largest bias in absolute value. All industry-level methods except Easton overestimate the cost of capital by about $1.1 \%$ on average.

We suspect that the firm-level methods generate biased ICC estimates because they rely on incorrect assumptions about the growth rate. Standard valuation analysis suggests that ICC methods should be more biased upward if they assume a growth rate that is too high. Then the upward bias in the growth rate would translate into higher model valuations, and, accordingly, a higher ICC. We analyze this point further by estimating implied long-term growth rates for each firm-level method in column (3) of 
Table 5. This growth rate equates the true value of each firm with the model value given the true cost of capital. The bias in the growth rate in column (4) of Table 5 is the difference between the implied growth rate and the growth rate assumed by the method. As expected, the biases are negative for the two residual income methods, but positive for GM. For all methods except ETSS the bias of the ICC is the same as the bias of the growth rate.

The positive bias of the three AEG methods follows from the fact that here the assumption is about the growth of abnormal earnings growth, i.e., about the growth of $\Delta a e$, whereas the growth rate in residual income methods refers to ae itself. ${ }^{20}$ For example, GM assumes growth of $\Delta a e$ of $1.5 \%$ per year, which implies much stronger earnings growth and therefore a higher valuation compared to the assumption of $1.5 \%$ of the level of abnormal earnings by Claus and Thomas (see Table 4 for the model assumptions). In fact, we can have positive growth of residual income $\left(\Delta a e_{t}>0\right)$ even if abnormal earnings growth itself is constant or even negative. The negative implied growth rate of $-17.4 \%$ for GM only implies that residual income will stop growing at some point, which does not rule out that it remains at a high level. A similar comment applies to MPEG, which assumes zero growth of abnormal earnings growth, which is still a much stronger assumption than the zero growth assumption of residual income made by GLS. We conclude from this discussion that the AEG methods with the standard growth assumptions in the literature are poorly calibrated.

The industry-level methods tend to display a low bias. Here the implied growth rates shown in column (3) are the growth rates predicted by these methods as part of the ICC estimation. While the bias for the implied growth rates is typically large, it does not translate one for one into a strong bias for the ICC.

Our results correspond broadly to those of Easton and Monahan (2005). We report their median ICC estimates for seven of their methods we also investigate in Table $5 .^{21}$ Their ICC estimates are equal to the true CoEC, which is unknown in their setting, plus the bias of the methods. Like them, we find the lowest ICC estimate for the PE ratio and the highest for GM, and observe that the ordering of their estimates for empirical data corresponds broadly to the ordering we obtain for simulated data.

\footnotetext{
${ }^{20}$ In some sense, $g$ in residual income models refers to the first derivative of the valuation function $V(g)$, whereas in AEG models $g$ refers to the second derivative of the valuation function.

${ }^{21}$ See their Table 2, which reports results for CT, GLS, GM, PE, PEG, MPEG, and Easton (2004).
} 
Accuracy. Accuracy refers to the typical error $\delta_{i}^{M}$ of the ICC estimates. We report the median absolute value and the standard deviation of $\delta_{i}^{M}$ in columns (6) and (7) of Table 5. The accuracy of ICC methods is on average low with a median absolute deviation of $2.4 \%$ and a standard deviation of $3.9 \%$ across all methods, which is large relative to a median cost of equity capital of $10 \%$. Both measures of accuracy vary significantly across methods, but are very consistent in terms of the implied rankings of the methods. ${ }^{22}$ Accuracy tends to be higher for the residual income methods and for the industry-level methods, but is consistently poor for all AEG methods. CT has the highest accuracy (1.5\% absolute deviation, $1.9 \%$ standard deviation), whereas the PEG ratio has the highest standard deviation (7.1\%) and GM has the highest absolute deviation (3.7\%).

We attribute the superiority of the residual income (RI) methods over the AEG methods to the modeling approach itself. In addition to the differences between the methods discussed above, RI methods make use of the information contained in the book value of equity, whereas AEG methods ignore this information, which leads to larger estimation errors for the ICC. We also suspect that RI methods perform better because they use longer forecasting horizons and therefore incorporate more information. In untabulated tests we develop a two-period version of the method of Claus and Thomas, which is more comparable to the AEG methods. ${ }^{23}$ We find that such a modified method performs worse than the original CT method, but still outperforms all AEG methods. This observation supports the conclusion that it is the modeling approach and not just the length of the forecast horizon that explains the difference between the results for AEG methods and for RI methods.

Among the industry-level methods, those that use realized values (O'Hanlon and Steele, Easton and Sommers) rank below those based on analyst forecasts in terms of accuracy. However, our simulation approach may exaggerate the difference between methods based on analyst forecasts and those based on realized values because we assume rational expectations, i.e. we equate analyst forecasts with forecasts based on the correct model, an issue we address in our robustness checks. Similarly, reported earnings in practice might have more predictive ability for future earnings than in our simulated economy (e.g., by impounding managers' private information).

\footnotetext{
${ }^{22}$ We also calculate the root mean squared error (RMSE), which implies almost the same ranking of methods as the standard deviation and is therefore not tabulated.

${ }^{23}$ We acknowledge that the AEG methods were designed to reflect frequently used valuation heuristics, and in particular to utilize solely the next two periods' analyst forecasts because of their frequent availability in practice. See e.g. Bradshaw (2002, 2004) and Easton (2004).
} 
Feasibility. We note that the applicability of a method to the widest possible sample is also a quality criterion, particularly in empirical applications. Some methods cannot calculate the implied cost of capital for each firm in our sample. In particular, all two-period AEG methods can be applied only to about $61 \%$ of the firms in our model economy (column (8) of Table 5), whereas the other methods generate estimates for the cost of capital in almost all cases. ${ }^{24}$

\subsection{Explainability}

We analyze explainability by running simple bivariate regressions of the implied cost of capital on the true cost of capital for each method and report the estimates for the intercept and slope as well as the R-squared from these regressions in Table 6. The table shows results for OLS (columns (1) to (3)) and for median regressions (columns (4) to (6)), which are more robust to outliers. The discussion below focuses on the OLS regressions.

[Insert Table 6 here.]

R-squared. Our first measure of explainability is the R-squared, which displays a striking variation across methods from 27\% (Easton and Sommers) to $89 \%$ (Easton). Firm-specific residual income methods perform best with R-squareds of $88 \%$ (CT) and 83\% (GLS), respectively. AEG methods perform worst, with R-squareds between $32 \%$ and $65 \%$ and an average of $48 \%$. Industry-level methods are in between with an average R-squared of $56 \%$. Methods that work with realized values (O'Hanlon and Steele, Easton and Sommers) perform poorly, as realizations seem to introduce significant noise into cost of capital calculations. Note that the same caveat as in the case of accuracy with respect to analyst forecasts and the predictive power of realized earnings applies here as well. The ranking in terms of R-squared and the ranking in terms of median bias from Table 5 tend to agree, i.e. a higher average bias (in absolute value) tends to correspond to lower explainability in terms of R-squared.

Regression-coefficient on CoEC. If the implied cost of capital methods were unbiased, then the univariate regressions should have an intercept of zero and a slope

\footnotetext{
${ }^{24}$ We restrict the algorithm to search for the implied cost of capital in the unit interval, but in a small number of cases it can only find solutions that are either negative or higher than $100 \%$. In theses cases the algorithm returns a missing value.
} 
coefficient of one. Table 5 reveals that this prediction is not borne out by the data. For all firm-level methods, the intercept is negative and the estimated CoEC-coefficient in the regression exceeds one significantly. For all industry-level methods except Easton the opposite conclusion holds.

Hence, while the average bias for most methods is small, many methods still have a low accuracy because they distort the estimates for companies with true CoEC that are either very low or very high. To illustrate this point, consider the ICC estimates for GLS when the true CoEC is five percentage points away from its mean of $10 \%$. Then the ICC estimate is biased downward by $1.3 \%$ if the true cost of capital is only $5 \%$, and the estimate is biased upward by $0.8 \%$ if the true cost of capital is $15 \% .^{25}$ By contrast, for three of the four industry-level methods, the opposite bias obtains. For example, for ETSS we obtain a positive bias of $3.2 \%$ if the true CoEC is $5 \%$, and a negative bias of $-0.9 \%$ if the true CoEC is $15 \%$. The effect is therefore economically large, even for those ICC methods where the average bias is small.

We label the deviation of the true CoEC from the ICC estimates distortion and refer to the regression coefficient on the true CoEC as the distortion coefficient. The effect differs for firm-level methods and for industry-level methods and we now investigate this phenomenon in more detail.

Distortion and the duration effect. In our model economy the DCF-value of each firm is a function of the true cost of capital: $P_{0}^{D G P}=P_{0}^{D G P}\left(r_{E}\right)$. (We suppress the reference to the firm index for notational convenience.) Similarly, each ICC method's valuation model implies a relationship between the implied cost of equity capital $r_{E}^{M}$ and the equity value: $P_{0}^{M}=P_{0}^{M}\left(r_{E}^{M}\right)$, where $M$ indexes the implied cost of capital methods. Hence, the model economy and each firm-level ICC method establish a relationship

$$
P_{0}^{D G P}\left(r_{E}\right)=P_{0}^{M}\left(r_{E}^{M}\right)
$$

From the implicit function theorem we then have:

$$
\frac{d r_{E}^{M}}{d r_{E}}=\frac{d P_{0}^{D G P}\left(r_{E}\right)}{d r_{E}} / \frac{d P_{0}^{M}\left(r_{E}^{M}\right)}{d r_{E}^{M}}
$$

The bivariate regressions in Table 6 simply estimate a linearized version of $\frac{d r_{E}^{M}}{d r_{E}}$ in (20). Hence, we obtain a large (small) slope coefficient in the regressions if the sensitivity

\footnotetext{
${ }^{25}$ We use the OLS estimates from Table 5 , for example: $r_{G L S}=-2.3 \%+5 \% *(1.2-1.0)=-1.3 \%$.
} 
of the firm value to the CoEC for the ICC's valuation model is smaller (larger) than the same sensitivity for the data generating process. We therefore need to understand the sensitivities $\frac{d P_{0}^{M}\left(r_{E}^{M}\right)}{d r_{E}^{M}}$ of firm values with respect to the cost of capital for each ICC method and for the simulation model. However, this sensitivity is nothing but the sensitivity of a present value relationship with respect to the discount rate, and we know that these sensitivities depend critically on how soon the cash flows (or earnings or dividends) are expected to arrive: The present values of cash flows that will arrive in the immediate future are not sensitive to the discount rate, whereas the present values of more distant cash flows are more sensitive. In the Appendix, we formalize this intuition by relying on the notion of equity duration developed in Dechow, Sloan, and Soliman (2004). Here we summarize the three main features of equity duration, which we denote by $D U R$, and defer technical details to the Appendix:

- Equity duration measures the average maturity of future cash flows (or dividends) discounted in a present value relation. Firms whose cash flows or dividends are expected to arrive in the more distant future therefore have a larger equity duration.

- Duration increases with the expected future growth rate of the firm, i.e., growth stocks have larger equity durations compared to value stocks. This relationship is intuitive, because for faster growing firms, more of their value derives from cash flows that are expected to arrive in the distant future.

- The sensitivity of firm value with respect to the CoEC is proportional to the equity duration of the firm. In particular, the sensitivity from (20) is given by

$$
\frac{d r_{E}^{M}}{d r_{E}}=\frac{D U R^{D G P}}{D U R^{M}}
$$

where $D U R^{D G P}$ is the equity duration implied by the data generating process, and $D U R^{M}$ is the duration implied by the ICC method for the same firm. Hence, $\frac{d r_{E}^{M}}{d r_{E}}$ is simply the ratio of the duration of the data generating process and that of the ICC method.

From the last property and the fact that $D U R^{D G P}$ is the same for all methods, it follows immediately that the regression coefficient on the true CoEC in Table 6 should be approximately equal to to $D U R^{D G P} / D U R^{M}$. We calculate the equity duration for each ICC method using equation (28) from the appendix, and report the median values 
in column (7) of Table $6 .{ }^{26}$ Our fitted DCF model generates a median equity duration of $D U R^{D G P}=18.91$ years, i.e. the average cash flow in the model economy is almost 19 years away. By comparison, the median duration of the ICC methods ranges from 12.5 years (Easton) to 39.3 years (Easton and Sommers). These numbers compare to the estimate of 15 years of Dechow, Sloan, and Soliman (2004). However, their method is slightly different from ours and they assume a higher cost of capital. ${ }^{27}$ Based on (21) we also calculate the ratio of $D U R^{D G P}$ and $D U R^{M}$ for each firm and report the mean and median of this ratio in columns (8) and (9) of Table 6.

From comparing the distortion coefficients with the duration measures, and especially with the mean and median of the duration ratio, in Table 6 we can observe that they are closely aligned. ${ }^{28}$ We do not expect this relationship to be perfect because we are trying to capture the nonlinear relationship (20) with a linear regression and can safely conclude that (21) yields a very good approximation for our purposes. We can therefore attribute the pattern of distortion coefficients in Table 6 to the fact that the equity duration measures implied by the firm-level ICC methods deviate from the equity duration in our fitted model economy. We refer to this effect, which relates the distortion of the cost of capital to the duration of the ICC method, as the duration effect.

From the discussion above we expect that the main driver of the disparities between the equity duration of the data generating process and that of the ICC methods are the different assumptions about growth. From comparing the implied growth rates in Table 5 and the duration values in Table 6 we can see that there is such a relationship, although the growth rates are only available for seven methods and not strictly comparable because, as we remarked in the discussion of the bias, the growth rates of residual income cannot be compared to those of abnormal earnings growth.

In addition to the duration effect, the distortion coefficient for the industry-level methods is also affected by a second feature of these methods. All industry-level methods assume that growth and the cost of capital are the same for all firms within an

\footnotetext{
${ }^{26}$ We calculate the derivative $d P_{0} / d r_{E}$ numerically from (28) by evaluating the average change in the value implied by a one basis point change in $r_{E}$.

${ }^{27}$ Dechow, Sloan, and Soliman (2004) calculate equity durations implied by observed stock prices whereas we use rational forecasts of future cash flows to determine equity durations. Moreover, they assume a level perpetuity realized after ten years, which by construction leads to lower durations compared to our model with perpetual growth.

${ }^{28}$ The mean value of $D U R^{D G P} / D U R^{M P E G}$ in Table 6 is distorted by one single outlier for which the ratio exceeds 10,000 . Removing this outlier leads to a value of 1.26 , which is in line with the median value of 1.21 .
} 
industry, which is not the case for our simulations. As a result, the variables in the regressions suffer from an errors-in-variables problem, which causes an attenuation bias for the slope coefficients and leads to a reduced sensitivity of the ICC to the true CoEC. ${ }^{29}$ The bias decreases with the R-squared of the regression, which explains why the distortion coefficient and the R-squareds for the four industry-level methods are closely related and why the distortion coefficient for Easton's method is above one as it also has an R-squared of $89 \%$ and therefore little attenuation bias.

Finally, we note that the distortion effect is unrelated to other factors that may influence the cost of capital. As remarked above, our simulated economy neither features the effects of size, stock market liquidity, transparency, and other factors that may affect companies' cost of capital, nor does it model forecast bias on part of the analysts. These factors play an important role in practice and would have to be added as controls in regressions based on empirical observations.

Bias and distortion. Finally, we observe that the bias of the ICC methods is closely related to the distortion coefficient. The relationship between distortion and bias can be understood from Figure 2, which shows the relationship between firm value and the CoEC for the simulated values (solid line) and for two typical firm-level ICC valuation models (dotted line and dashed line). Now consider firm 1, which has a low true cost of capital $r_{E, 1}$ and a high corresponding equity value $P_{0,1}^{D G P}$, which we can read off the function for the data generating process. Firm-level ICC method $M i$ now searches for a cost of equity capital $r_{E, 1}^{M i}$ for firm 1 that equates this equity value with that of the model from (19). The resulting error in the cost of capital estimate is then $r_{E, 1}^{M i}-r_{E, 1}$, which is negative and equal in absolute value to the horizontal distance between the two curves. The same argument applies again to another firm 2, which has higher true cost of capital $r_{E, 2}$, a low equity value $P_{0,2}^{D G P}$, and a positive error $r_{E, 2}^{M i}-r_{E, 2}$. In this case, method 1 (dotted line), which exemplifies residual income methods, leads to a negative bias because the underestimation when the true cost of capital are low is much larger in absolute value than the overestimation when the true cost of capital is high. By contrast, method 2 (dashed line), which is more typical for AEG methods, leads to a positive bias because the overestimation is much larger. By experimenting with the functions for different methods we found that a longer forecasting horizon leads to a steeper function and therefore to a negative bias, whereas shorter forecasting horizons

\footnotetext{
${ }^{29}$ Easton (2004), Section IV discusses this problem. The attenuation bias moves the slope coefficients towards zero.
} 


\section{Figure 2: Value sensitivity for high and low value firms}

This figure shows the convexity effect by illustrating the deviations arising for firms with with high versus low firm values. The graphs highlight the value sensitivities with respect to changes in the CoEC of the underlying data generating process (solid line) and two representative firm-level ICC methods (dashed and dotted lines). We plot firms' cost of equity capital on the horizontal axis and the market equity value on the vertical axis.

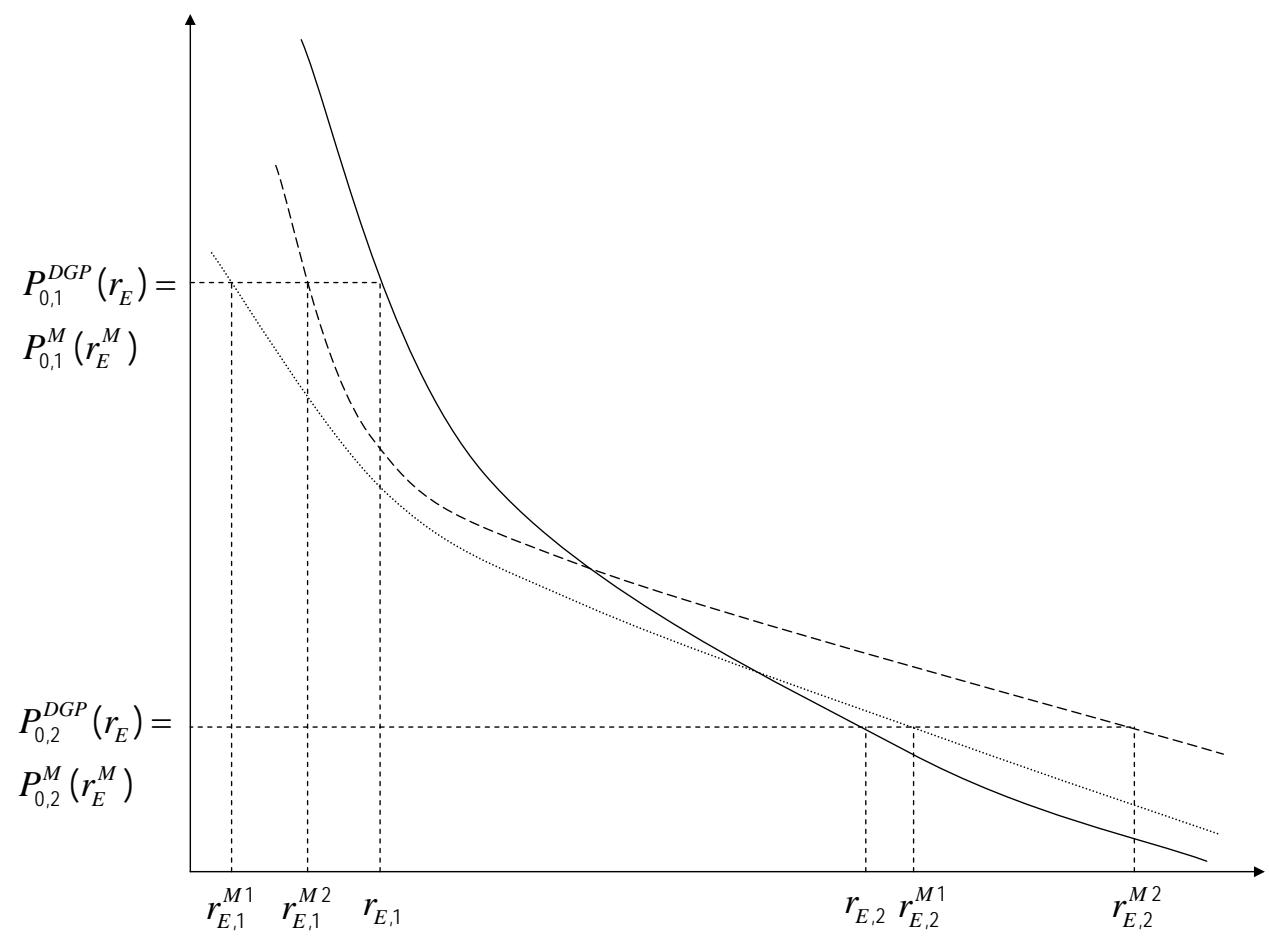

lead to shallower functions and a positive bias.

\section{Combining ICC methods}

In the previous section we diagnose the strengths and deficiencies of the ICC methods. In this section we turn to potential improvements in these methods. More specifically, we consider several different ways of combining individual ICC methods. The first method was suggested by Hail and Leuz (2006, 2009), who use an equally weighted average of the methods of CT, GLS, GM, and the PEG ratio. In similar spirit, Dhaliwal, Krull, and Li (2007) use the mean of CT, GLS, and GM. The third combination weights 
all ten methods equally. The fourth approach applies principal component analysis and observes that the first component captures $71 \%$ of the variation in the ICC methods. ${ }^{30}$ This observation supports the notion that the ICC methods measure one common factor. Also, the loadings of all methods on the first principal component are positive and vary in a narrow range from 0.25 to 0.36 (these results are not tabulated).

Next, we construct weights from regression analysis as follows. We run regressions of the true cost of capital $r_{E}$ on each of the ICC measures. The results are reported in Table 7 .

[Insert Table 7 here.]

Specification (1) is a standard OLS-regression without any restrictions. The Rsquared of this regression is $95.6 \%$, so all ten methods combined leave only $4.4 \%$ of the true cost of capital unexplained. This observation reinforces the conclusion from principal component analysis that the ICC methods jointly capture a very large part of the variation in the cost of capital. If all ICC methods were unbiased and not distorted, then any combined method should result in regression coefficients that sum to one and in an intercept of zero and thereby generate the optimal weights for a combined method. However, combining the ICC measures in the way suggested by the coefficients from this regression implies that the weights sum to 0.70 , whereas the intercept is 0.042 . Regression (2) therefore restricts the regression coefficients to sum to one and sets the constant to zero. Regression (3) requires in addition that weights be non-negative. Note that several regression coefficients are close to zero now, in particular all the coefficients for the AEG methods, except for the industry-level method of Easton.

Finally, we consider two simple combinations that emanate from the regression analysis. Observe from regression (3) in Table 7 that only four methods are given significant weights (CT, GLS, ETSS, and Easton) and that the weights are broadly similar. We therefore construct an equally weighted average of these four methods and label it "Equally weighted - top four" in the tables. Finally, we simplify even further and combine only GLS and ETSS, the best two methods, with equal weights and report it as "GLS \& ETSS" in the tables. The reasoning for this combination is that we mainly need to remove the distortion effect in order to simultaneously improve bias, accuracy, and explainability. However, the distortion coefficient from firm-level methods is above one, resulting in a negative bias, whereas the distortion coefficient from industry-level

\footnotetext{
${ }^{30}$ Hail and Leuz (2009) also use principal component analysis to extract a common factor from ICC estimates.
} 
methods is below one, resulting in a positive bias. Combining two methods, one from each category, should therefore suffice to address the main shortcomings we diagnose in Section 4.

[Insert Table 8 here.]

Table 8 reports the key evaluation criteria we used in Section 4 and applies them to the combined methods. With R-squareds up to 94.3\%, many ICC combinations capture a significant portion of the true cost of capital and improve substantially relative to individual methods. Note that we have optimized the weights for the regression-based methods to match the characteristics of our simulated sample. We can therefore not legitimately compare the out-of-sample tests for ad hoc combinations with the in-sample tests for regression-based methods.

The improvement for some of the combined methods is significant relative to the individual methods. From the in-sample methods, the weighting scheme prescribed by regression (2) performs best, with a median bias of $-0.1 \%$, a standard deviation of $1.0 \%$, a distortion coefficient of 0.99 , and an R-squared of $93.6 \%$. Hence, this method is practically unbiased and highly accurate and captures the true cost of capital almost perfectly. Specifically, it outperforms the method based on unrestricted regressions, which creates significant distortion, and the method based on principal components. However, the method based on regression (2) requires the input of all ten methods and can be computed only for the sample for which all these methods can be estimated.

From the ad hoc methods, "Equally weighted - top four" performs almost as well as the best regression-based method, with a bias of $-0.3 \%$, a standard deviation of $1.1 \%$, and a distortion coefficient of 1.06. This combination outperforms all other ad hoc methods as well as all individual methods. Recall that the lowest standard deviation we observe among individual methods before is for CT (1.9\%, see Table 5), which then has substantially more bias and distortion. The "GLS-ETSS" combination performs only marginally worse on all dimensions in our economy. It provides a useful trade-off between simplicity and the ability to capture the true CoEC in most circumstances, and may therefore be recommendable for applications. By contrast, the ad hoc methods used in the prior literature (Hail and Leuz, Dahliwal et al.) perform significantly worse, mostly because they include firm-level AEG methods, which also limits their applicability. 


\section{Extensions and robustness checks}

All our results in the previous two sections rely on the simulated model and on the parameterization we describe in Section 2 above. In this section we check to what extent the results we report above may reflect features of the simulation model rather than features of the ICC methods we wish to analyze. We want to make sure that the salient properties of the ICC methods pertain to these models and not to the simulation model.

[Insert Table 9 here.]

Table 9 summarizes the results for three different robustness checks (columns (2) to (4)). For convenience, we repeat the corresponding results for the baseline model in column (1). In panel A of the table we report the median of six key parameters for the simulated values. In the other panels we report the bias (median, panel B), accuracy (standard deviation, panel C) and explainability (distortion coefficient, panel D; Rsquared, panel E) for the ten individual ICC methods and for two selected combined methods.

Alternative steady state model. In Section 2.2 above we justify the simulation parameters with reference to the empirical sample, but deviate from the empirical percentage-of-sales parameters in order to better match the valuation ratios. In the alternative scenario in column (2) of Table 9 we use a parameterization that matches the empirical depreciation-to-sales ratio and the equity-to-sales ratio more closely by using 3.5\% for the former (median in Compustat sample: $3.6 \%$ ) and $50 \%$ for the latter (sample median: 48.9\%). With these parameters the steady-state value for the equityto-sales ratio is $48.8 \%$ from (8).

As a result, valuations for this parameterizations are somewhat higher with a market-to-book ratio of 1.57 and a PE ratio of 14.09, where the latter now exceeds the empirical median by 2.3 , which renders this parameterization somewhat worse in terms of valuation. The mean bias tends to become negative, but stays about the same in absolute value. Accuracy improves for all methods, but the ranking across methods stays the same as in the baseline case. Similarly, the distortion coefficient declines, but the patterns across methods is not affected. R-squareds also improve slightly. The two combined methods still improve significantly on each of the individual methods for all 
parameters except for the distortion coefficient, where the GLS-ETSS combination now overweighs ETSS. Overall, the general conclusions we derived above are not affected.

Analyst forecast bias. In our baseline model we generate forecasts from the vector autoregressive model (1) and (2) and the business planning model. This approach implicitly assumes rational expectations and unbiased forecasts. However, these forecasts from the VAR model take the place of analyst forecasts in the implementation of the ICC methods, and a large literature documents that analyst forecasts are biased (see e.g. Brown 1993, Kothari 2001). Moreover, Easton and Sommers (2007) argue that analyst forecasts bias ICC methods. We therefore repeat our analysis by creating an optimistic bias and report the results in column (3) of Table 9. Starting from the baseline scenario, we calculate the ROE for each firm and each period for which the ICC methods require analyst forecasts, and then add $3 \%$ to this ROE value. ${ }^{31}$ We then recalculate residual income and abnormal earnings growth with this increased ROE. Note that this modification does not change what really happens in our economy (hence, in panel A, the numbers in column (3) are the same as those in column (1)). Similarly, the results in panels $\mathrm{B}$ to $\mathrm{E}$ for the ICC methods that rely on realized returns are unaffected. As expected, analyst optimism leads to higher ICC estimates and generates a larger positive bias, in particular for the residual income methods, ETSS, and Easton. Whereas the average bias across the eight methods that use analyst forecasts is $1.7 \%$ for the baseline model, it is $2.3 \%$ with the simulated analyst forecast bias. The results for accuracy are slightly worse with the analyst forecast bias and the distortion effect also gets somewhat worse. Overall, however, the analyst forecast bias erodes only a small part of the advantage of methods based on analyst forecasts relative to those based on realizations.

Dividend discount model. Finally, we also check for the impact of the valuation model we use to generate simulated firm values. In our baseline model we use a standard DCF model to generate firm values. Our business planning model also generates expectations for future dividends, based on the assumed values for the plowback rate and we therefore repeat the analysis with firm values generated by the dividend discount

\footnotetext{
${ }^{31}$ Easton and Sommers (2007) find 3 percentage points CoEC bias. We use these 3 percentage points as an estimate for the bias of ROE forecasts. Although the magnitude of analysts' optimism reported in the literature varies considerably across studies (Kothari 2001), and is typically expressed in percentage of stock price or per share, our 3 percentage points above ROE forecasts are in the upper range of reported optimism.
} 
model. Column (4) panel A shows that this has a large impact on firm values. Firm values are now somewhat lower and also lower than in the Compustat sample. ${ }^{32}$ Otherwise, very little changes with respect to the analysis of the ICC methods. Whereas the estimates for bias and R-squared based on the dividend discount model are very similar to those obtained with the DCF model, those for accuracy and distortion are somewhat worse. However, all qualitative conclusions still hold.

Industry-level methods (not tabulated). In our simulated economy, industrylevel methods have specific properties, which add to the construction of combined methods. We run two robustness checks adressing potential issues regarding the validity of these results.

First, our assumptions about the dispersion of the true cost of capital are somewhat ad hoc because little can be known about the parameters of the distribution of the true cost of capital. Our baseline specification assumes that the true cost of capital have an overall standard deviation of $4.2 \%$ from (10), where most of the variation comes from the variation between industries and very little comes from the variation between firms within the same industry. We change the parameterization so that the within-industry variation equals the between-industry variation, holding the overall standard deviation constant. As expected, the results are very similar for the firm-level methods, but industry-level methods perform worse in terms of accuracy and explainability, and the optimal weights when constructing combined methods would need to change. Nevertheless, even under this demanding scenario, the combined methods that give some weight to industry-level methods are generally at least at par with the individual methods in terms of accuracy and explainability (R-squared, distortion-coefficient).

Second, we perform a simulation where we draw 2,000 industries with only 10 firms each in order to investigate the performance of ICC methods for small industries, an issue regression-based methods face in real world applications. Unsurprisingly, the accuracy of industry-level methods that rely on realized values instead of forecasts declines substantially. Interestingly, ETSS and Easton are now less distorted, i.e., the distortion coefficient is closer to one. The combined methods we advocate still perform better than almost all other approaches.

\footnotetext{
${ }^{32}$ Recall that Modigliani and Miller (1961) dividend irrelevance does not hold here. In their argument, cash that is distributed and cash that is retained both earn the cost of capital, whereas in our model cash retained in the firm is reinvested and generates the same return as all other capital invested in the firm.
} 
Further checks (not tabulated). We perform several further robustness checks, but do not tabulate the results here. More specifically, we modify the parameters of the VAR process to generate more or less persistence in the response of EBITDA and sales growth to a shock, and we also change the length of the detailed planning period to 25 years and to 75 years, respectively. The change in the time series parameters has no discernible impact on our main inferences. We therefore do not pursue this avenue further and conclude that our results are robust to perturbations of the times series model we use.

Shortening the time horizon for the planning period in our model reduces valuations, whereas lengthening the time horizon increases valuations. This is simply a consequence of the fact that we assume zero growth for the horizon value, so that longer detailed planning periods also imply more growth. This modification has a corresponding impact on the bias, but only a very marginal impact on accuracy. The average distortion coefficient also does not change much with the horizon of the model, but the difference in distortion between firm-level methods and industry-level methods increases with the time horizon. Consequently, the assessment of the combined methods does not change.

Our assumption of a plowback rate of $50 \%$ differs from the empirical rate of $65 \%$ in our Compustat sample. We performed an additional check where we set the plowback rate to $65 \%$ and found that its main impact is to reduce the market-to-book ratio to 1.33, significantly below the median empirical ratio of 1.61. All findings we discuss above are robust with respect to this change.

\section{Conclusions}

In this paper we compare implied cost of capital methods by using a simulation approach. We calibrate a simulated economy to a large sample of real-world data. We obtain a number of robust conclusions with regard to the properties of the methods as well as to their application in empirical studies.

Within the group of firm-level methods, residual income methods uniformly dominate abnormal earnings growth methods. Abnormal earnings growth methods have a significant positive bias, whereas residual income methods have a negative bias that is less than half of that of abnormal earnings growth methods in absolute value. Similar conclusions also hold for accuracy, which we measure by the standard deviation of the estimation errors, and for the R-squared of regressions of the ICC estimates on the true 
cost of equity capital.

The essential difference between abnormal earnings growth methods and residual income methods is the modeling of abnormal earnings. Whereas residual income methods model the growth of future abnormal earnings, abnormal earnings growth methods model the changes in future abnormal earnings. Abnormal earnings growth methods therefore take an approach that focuses on the first derivative of abnormal earnings instead of abnormal earnings themselves, and this approach seems to lose information that is critical for valuation purposes and leads to less reliable forecasts.

The performance of industry-level methods that simultaneously estimate the cost of capital and expected growth is somewhere in between the two groups of firm-level methods. Especially those industry-level methods that rely on analyst forecasts perform remarkably well and in some cases come close to the performance of residual income methods, even if we allow for a $3 \%$ bias in analyst forecasts.

In addition to the average bias of each method we also consider whether the methods distort the true cost of capital by running regressions of the ICC estimates against the true cost of equity capital. If the methods are not distorted, then the slope coefficient in these regressions should be one, but it is in fact larger than one for all firm-level methods and smaller than one for three out of four industry-level methods. We attribute this finding to two factors. The first factor is the equity duration of the methods, i.e., how far earnings growth is projected into the future. The second factor is the errors-invariables problem that arises in industry-level methods if the firms within the same industry do not all have the same growth rate and the same cost of capital.

We explore improvements of implied cost of capital estimates by aggregating several estimates through the calculation of averages of the individual methods. We identify weighting schemes based on regression analysis and principal components analysis as well as ad hoc, equally weighted methods that work well. The analysis of the individual methods suggests that residual income methods and industry-level methods based on forecasts provide good components for combined methods because they are biased and distorted in the opposite direction. Combinations that give equal weights to both classes of methods therefore benefit from compensating errors and outperform all individual methods.

Researchers have come to rely on ICC estimates as proxies for the cost of capital in a range of applications when testing related economic theories. ${ }^{33}$ For these applications

\footnotetext{
${ }^{33}$ Examples include Botosan (1997) on voluntary disclosure; Hail and Leuz (2006) on the impact of legal institutions and securities regulation; Pastor, Sinha, and Swaminathan (2008) on the risk-return
} 
accuracy and bias are less relevant, because they mainly rely on estimates that capture a large part of the variation in the cost of capital. In our simulations, individual ICC methods capture up to $89 \%$ and one of the combined methods captures up to $94 \%$ of the variation in the true cost of equity capital, which provides an optimistic outlook on the use of ICC estimates in such research. As a note of caution, we add that some sources of noise that may be relevant in empirical settings are not included in our simulated economy.

All our conclusions are limited by the simulation approach we use here, which relies on a business planning model, the time-series modeling of the dynamics of profitability and sales growth, and its calibration towards median valuation ratios of the CRSPCompustat universe. We had little guidance from the literature on this effort, which has primarily focused on the short-term dynamics of key accounting variables (e.g. Bernard and Thomas 1989). Little seems to be known about the long-term time-series properties of key accounting variables or the dynamics of the main value drivers (see Dechow, Kothari, and Watts 1998 for a short-term model) and more work is needed here.

trade-off; Chen, Kacperczyk, and Ortiz-Molina (2009) on the influence of labor relations; Daske (2006) on voluntary and Daske, Hail, Leuz, and Verdi (2008) on mandatory IFRS adoption; Hail and Leuz (2009) on cross listings; and Hou and Van Dijk (2010) on the size effect. 


\section{References}

Arellano, M., and O. Bover, 1995, "Another Look at the Instrumental-Variable Estimation of Error-components Models", Journal of Econometrics, 68(1), 29-51.

Balachandran, B. V., R. Balakrishnan, and K. Sivaramakrishnan, 1997, "On the Efficiency of Cost-Based Decision Rules for Capacity Planning", Accounting Review, $72(4), 599-619$.

Barth, M. E., and S. Kallapur, 1996, "The Effects of Cross-Sectional Scale Differences on Regression Results in Empirical Accounting Research", Contemporary Accounting Research, 13(2), 527-567.

Beaver, W., P. Kettler, and M. Scholes, 1970, "The Association between Market Determined and Accounting Determined Risk Measures", The Accounting Review, 45(4), $654-682$.

Bernard, V. L., and J. K. Thomas, 1989, "Post-Earnings-Announcement Drift: Delayed Price Response or Risk Premium?", Journal of Accounting Research, 27(Supplement), $1-36$.

Botosan, C. A., 1997, "Disclosure Level and the Cost of Equity Capital", The Accounting Review, 72(3), 323-349.

Botosan, C. A., and M. A. Plumlee, 2005, "Assessing Alternative Proxies for the Expected Risk Premium", Accounting Review, 80(1), 21-53.

Botosan, C. A., M. A. Plumlee, and H. J. Wen, 2010, "The Relation Between Expected Returns, Realized Returns, and Firm Characteristics", Working Paper, University of Utah.

Bradshaw, M. T., 2002, "The Use of Target Prices to Justify Sell-Side Analysts' Stock Recommendations", Accounting Horizons, 16(1), 27-41.

— , 2004, "How Do Analysts Use Their Earnings Forecasts in Generating Stock Recommendations?", The Accounting Review, 79(1), 25-50.

Brav, A., R. Lehavy, and R. Michaely, 2005, "Using Expectations to Test Asset Pricing Models", Financial Management, 34(3), 31-64. 
Brooks, C., 2008, Introductory Econometrics for Finance. Cambridge University Press, 2nd edn.

Brown, L. D., 1993, "Earnings Forecasting Research: Its Implications for Capital Markets Research", International Journal of Forecasting, 9(3), 295-320.

Chen, H., M. T. Kacperczyk, and H. Ortiz-Molina, 2009, "Labor Unions, Operating Flexibility, and the Cost of Equity", Journal of Financial and Quantitative Analysis (Forthcoming).

Claus, J., and J. Thomas, 2001, "Equity Premia as Low as Three Percent? Evidence from Analysts' Earnings Forecasts for Domestic and International Stocks", Journal of Finance, 56(5), 1629-1666.

Daske, H., 2006, "Economic Benefits of Adopting IFRS or US-GAAP: Have the Expected Cost of Equity Capital Really Decreased?", Journal of Business Finance \& Accounting, 33(3/4), 329-373.

Daske, H., L. Hail, C. Leuz, and R. Verdi, 2008, "Mandatory IFRS Reporting around the World: Early Evidence on the Economic Consequences", Journal of Accounting Research, 46(5), 1085-1142.

Dechow, P. M., S. P. Kothari, and R. Watts, 1998, "The Relation Between Earnings and Cash Flows", Journal of Accounting and Economics, 25(2), 133-168.

Dechow, P. M., R. G. Sloan, and M. T. Soliman, 2004, "Implied Equity Duration: A New Measure of Equity Risk", Review of Accounting Studies, 9(2-3), 197-228.

Dechow, P. M., R. G. Sloan, and A. P. Sweeney, 1995, "Detecting Earnings Management", The Accounting Review, 70(2), 193-225.

Dhaliwal, D., L. Krull, and O. Z. Li, 2007, "Did the 2003 Tax Act reduce the cost of equity capital?", Journal of Accounting and Economics, 43(1), 121-150.

Dorn, D., G. Huberman, and P. Sengmueller, 2008, "Correlated Trading and Returns", Journal of Finance, 63(2), 885-920.

Easton, P., 2009, "Estimating the Cost of Capital Implied by Market Prices and Accounting Data", Foundations and Trends in Accounting, 2(4), 241-364. 
Easton, P., G. Taylor, P. Shroff, and T. Sougiannis, 2002, "Using Forecasts of Earnings to Simultaneously Estimate Growth and the Rate of Return on Equity Investment", Journal of Accounting Research, 40(3), 657-676.

Easton, P. D., 2004, "PE Ratios, PEG Ratios, and Estimating the Implied Expected Rate of Return on Equity Capital", Accounting Review, 79(1), 73-95.

Easton, P. D., and S. J. Monahan, 2005, "An Evaluation of Accounting-Based Measures of Expected Returns", Accounting Review, 80(2), 501-538.

Easton, P. D., and G. A. Sommers, 2007, "Effect of Analysts' Optimism on Estimates of the Expected Rate of Return Implied by Earnings Forecasts", Journal of Accounting Research, 45(5), 983-1015.

Elton, E. J., 1999, "Expected Return, Realized Return, and Asset Pricing Tests", Journal of Finance, 54(4), 1199-1220.

Fama, E. F., and K. R. French, 1992, "The Cross-Section of Expected Stock Returns", Journal of Finance, 47(2), 427-465.

— , 1997, "Industry Costs of Equity", Journal of Financial Economics, 43(2), 153193.

— , 2002, "The Equity Premium”, Journal of Finance, 57(2), 637-660.

Francis, J., 1990, "Accounting for Futures Contracts and the Effect on Earnings Variability", Accounting Review, 65(4), 891-910.

Francis, J., P. Olsson, and D. R. Oswald, 2000, "Comparing the Accuracy and Explainability of Dividend, Free Cash Flow and Abnormal Earnings Equity Value Estimates", Journal of Accounting Research, 38(1), 45-70.

Gebhardt, W. R., C. M. C. Lee, and B. Swaminathan, 2001, "Towards an Implied Cost of Capital", Journal of Accounting Reserach, 39(1), 135-175.

Gode, D., and P. Mohanram, 2003, "Inferring the Cost of Capital Using the OhlsonJuettner Model", Review of Accounting Studies, 8(4), 399-431.

Greenball, M. N., 1968, "The Accuracy of Different Methods of Accounting for Earnings - A Simuluation Approach", Journal of Accounting Research, 6(1), 114-129. 
Guay, W., S. Kothari, and S. Shu, 2005, "Properties of Implied Cost of Capital Using Analysts' Forecasts", MIT Sloan Working Paper.

Hail, L., and C. Leuz, 2006, "International Differences in the Cost of Equity Capital: Do Legal Institutions and Securities Regulation Matter?", Journal of Accounting Research, 44(3), 485-531.

— , 2009, "Cost of Capital Effects and Changes in Growth Expectations around U.S. Cross-Listings", Journal of Financial Economics, 93(3), 428-454.

Healy, P. M., S. C. Myers, and C. D. Howe, 2002, "R\&D Accounting and the Tradeoff Between Relevance and Objectivity", Journal of Accounting Research, 40(3), 677-710.

Hou, K., and M. A. Van Dijk, 2010, "Profitability Shocks and the Size Effect in the Cross-Section of Expected Stock Returns", Fisher College of Business Working Paper.

Hou, K., M. A. Van Dijk, and Y. Zhang, 2010, "The Implied Cost of Capital: A New Approach", Fisher College of Business Working Paper.

Hughes, J. S., J. Liu, and J. Liu, 2009, "On the Relation Between Expected Returns and Implied Cost of Capital", Review of Accounting Studies, 14(2-3), 246-259.

Knechel, W. R., 1988, "The Effectiveness of Statistical Analytical Review as a Substantive Auditing Procedure: A Simulation Analysis", Accounting Review, 63(1), 74-95.

Kothari, S., J. S. Sabino, and T. Zach, 2005, "Implications of Survival and Data Trimming for Tests of Market Efficiency", Journal of Accounting and Economics, 39(1), $129-161$.

Kothari, S. P., 2001, "Capital Markets Research in Accounting", Journal of Accounting and Economics, 31(1-3), 105-231.

Labro, E., and M. Vanhoucke, 2007, "A Simulation Analysis of Interactions among Errors in Costing Systems", Accounting Review, 82(4), 939-962.

— , 2008, "Diversity in Resource Consumption Patterns and Robustness of Costing Systems to Errors", Management Science, 54(10), 1715-1730.

Lambert, R. A., 2009, "Discussion of "On the Relation between Expected Returns and Implied Cost of Capital"'", Review of Accounting Studies, 14(2-3), 260-268. 
Lambert, R. A., and D. F. Larcker, 1989, "Estimating the Marginal Cost of Operating a Service Department when Reciprocal Services Exist", Accounting Review, 64(3), 449-467.

Lee, C. M. C., D. Ng, and B. Swaminathan, 2009, "Testing International Asset Pricing Models Using Implied Costs of Capital", Journal of Financial and Quantitative Analysis, 44(2), 307-335.

Lettau, M., and J. A. Wachter, 2007, "Why Is Long-Horizon Equity Less Risky? A Duration-Based Explanation of the Value Premium", Journal of Finance, 62(1), 5592.

Love, I., and L. Zicchino, 2006, "Financial Development and Dynamic Investment Behavior: Evidence from Panel VAR", Quarterly Review of Economics and Finance, $46(2), 190-210$.

Lundblad, C., 2007, "The Risk Return Tradeoff in the Long Run: 1836-2003", Journal of Financial Economics, 85(1), 123-150.

Lundholm, R. J., and R. Sloan, 2007, Equity Valuation and Analysis with eVal. McGraw-Hill Irwin, 2 edn.

Modigliani, F., and M. H. Miller, 1961, "Dividend Policy, Growth, and the Valuation of Shares", Journal of Business, 34(4), 411-433.

O’Hanlon, J., and A. Steele, 2000, "Estimating the Equity Risk Premium Using Accounting Fundamentals", Journal of Business Finance $\&$ Accounting, 27(9/10), 10511083.

Ohlson, J., and Z. Gao, 2006, "Earnings, Earnings Growth and Value", Foundation and Trends in Accounting, 1(1), 1-70.

Pastor, L., M. Sinha, and B. Swaminathan, 2008, "Estimating the Intertemporal RiskReturn Tradeoff Using the Implied Cost of Capital", Journal of Finance, 63(6), 28592897.

Pastor, L., and R. F. Stambaugh, 1999, "Costs of Equity Capital and Model Mispricing", Journal of Finance, 54(1), 67-121. 
Penman, S. H., 2009, Financial Statement Analysis and Security Valuation. McGrawHill/Irwin, 4th edn.

Rees, W., and C. Sutcliffe, 1993, "Mathematical Modelling and Stochastic Simulation of Accounting Alternatives", Journal of Business Finance $\&$ Accounting, 20(3), 351-358. 


\section{Appendix}

\section{Steady-state values for financial ratios:}

The plowback rate is defined as $p b=\left(e_{t}-d_{t}\right) / e_{t}$. With this definition, the clean surplus relation (5) becomes $b v_{t}=b v_{t-1}+e_{t} p b$. We can therefore write the growth rate of equity $g_{E, t}$ as:

$$
g_{E, t}=\frac{b v_{t}-b v_{t-1}}{b v_{t-1}}=\frac{e_{t} p b}{b v_{t-1}}=r o e_{t} p b .
$$

In a steady state, the growth rates for sales and for the book value of equity are the same, which gives (7).

Pre-tax income is $S_{t}(m-d)$, so that net income can be expressed as:

$$
e_{t}=(m-d)(1-T) S_{t}
$$

The growth rate of equity from (22) becomes:

$$
g_{E, t}=\frac{p b(m-d)(1-T) S_{t}}{b v_{t-1}}
$$

We can rewrite $b v_{t}=\left(1+g_{E, t}\right) b v_{t-1}$ and, in a steady state, $g_{E, t}=g_{S, t}$. Substituting these expressions and rearranging gives (8).

\section{Duration}

Let $f c f_{t}$ be the expected free cash flow of the firm at time $t$. Let $D U R$ be the equity duration for the data generating process and define it as:

$$
D U R=\frac{1}{1+r_{E}} \sum_{t=1}^{\infty} t \frac{f c f_{t}}{P_{0}^{D G P}\left(1+r_{E}\right)^{t}} .
$$

is defined as a weighted average of the maturities of all future free cash flows (earnings, dividends, etc.), where the weight for each maturity is the proportion of the corresponding cash flow in the value of the firm: ${ }^{34}$

The concept of duration can also be applied to valuation models independently of

\footnotetext{
${ }^{34}$ We premultiply by $1 /(1+r)$ for convenience. Our definition of duration in equation (25) corresponds to the definition of "modified duration" in the literature because we divide by $1+r_{E}$. This definition facilitates the exposition because it eliminates the factor $1+r_{E}$ from (28).
} 
whether they discount cash flows, dividends, or abnormal earnings. This follows from a general property of duration, which allows us to easily obtain the duration for the data generating process and for each of the models. Let $P_{0}$ be the current equity value:

$$
P_{0}=\sum_{t=1}^{t=\infty} f c f_{t}\left(1+r_{E}\right)^{-t}
$$

Then the first derivative is:

$$
\frac{d P_{0}}{d r_{E}}=-\sum_{t=1}^{t=\infty} t f c f_{t}\left(1+r_{E}\right)^{-(t+1)}
$$

Multiplying both sides of (27) by $1 / P_{0}$ yields

$$
-\frac{d P_{0}\left(r_{E}\right)}{d r_{E}} \frac{1}{P_{0}}=D U R
$$

Hence, the sensitivity of percentage changes in equity values with respect to the CoEC is equal to their duration. From (28) we can obtain the duration simply from calculating the first derivative of the respective valuation equation.

We demonstrate this claim for the simple case of dividends and the constant growth model:

$$
P_{0}^{\text {Gordon }}=\frac{d_{1}}{r_{E}-g}
$$

where $P_{0}^{\text {Gordon }}$ is the equity value according to the Gordon growth model for some constant dividend growth rate $g$ and dividend $d_{1}$. From (28) and (29) we have:

$$
D U R^{\text {Gordon }}=-\frac{d P_{0}^{\text {Gordon }}}{d r_{E}} \frac{1}{P_{0}^{\text {Gordon }}}=\frac{r_{E}-g}{d_{1}} \frac{d_{1}}{\left(r_{E}-g\right)^{2}}=\frac{1}{r_{E}-g} .
$$

We can proceed similarly with the valuation equations of all residual income and abnormal earnings growth models used by the ICC methods we discuss in this paper.

Claim 1: Equity duration measures average maturity. This claim follows directly from the definition and from observing that the weight $w_{t}$ of maturity $t$ is $f c f_{t}\left(1+r_{E}\right)^{t} / P_{0}$ and that $\sum_{t} w_{t}=1$. Then $D U R=\left(1+r_{E}\right)^{-1} \sum_{t} t w_{t}$. For example, the equity duration of a firm that has only one cash flow at time $T$ (all other cash 
flows are zero) is simply $T\left(1+r_{E}\right)^{-1}$ because then $w_{T}=1$. Hence, apart from the normalization factor $1 /\left(1+r_{E}\right)$, duration measures the average maturity of the cash flows associated with the firm.

Claim 2: Equity duration is an increasing function of the growth rate. Define the t-period growth rate of cash flows by $1+G_{t}=f c f_{t} / f c f_{0}$. Then from the definition of the weight $w_{t}$ above, $w_{t}=\left(1+G_{t}\right) f c f_{0}\left(1+r_{E}\right)^{t} / P_{0}$, which is increasing in the growth rate. Hence, for faster growing firms later maturities receive a higher weight so that the average maturity becomes larger. For the Gordon growth model, DU $R^{\text {Gordon }}$ increases with the constant growth rate $g$.

Claim 3: Derivation of equation (21). The claim in the text that the sensitivity of firm value with respect to the CoEC is proportional to the equity duration is expressed in (28). Apply the implicit function theorem to (19) to obtain:

$$
\frac{d P_{0}^{D G P}\left(r_{E}\right)}{d r_{E}} d r_{E}=\frac{d P_{0}^{M}\left(r_{E}^{M}\right)}{d r_{E}^{M}} d r_{E}^{M} \Rightarrow-D U R^{D G P} P_{0} d r_{E}=-D U R^{M} P_{0} d_{E}^{M}
$$

Dividing both sides by $-P_{0}$ and rearranging yields (21).

We note that duration analysis applies strictly only to firm-level methods and not to industry-level methods, because for the latter (19) does not hold individually for each firm. ${ }^{35}$

\footnotetext{
${ }^{35}$ Industry-level methods determine the growth rate endogenously, but the sensitivity of the ICC to the true cost of capital depends on the cash flow patterns for the entire portfolio and not on the patterns of the individual firm. Exploring this more intricate relationship analytically is beyond the scope of this appendix.
} 


\section{Tables}

\section{Table 1: Key financial ratios and model parameters}

This table shows summary statistics for a CRSP-Compustat sample of 8,036 firms with 96,917 firmyear observations between 1970 and 2009. The table includes univariate statistics for the main value drivers, percentages of sales and financial ratios of the sample firms using CRSP-Compustat data. All variables are winsorized at the $1 \%$-level. Payout consists of common dividends. Return on assets (equity) is defined as net income divided by the book value of total assets (equity). The price earnings ratio is computed as the share price divided by earnings per share (EPS), where EPS is net income divided by the number of common shares outstanding. Leverage is defined as book value of long term debt divided by total assets plus market capitalization minus book value of equity. The model parameters used later in the simulation framework are presented in the last column.

\begin{tabular}{lccccccc}
\hline & & & & & & Model \\
Variable & $\mathbf{2 5 \%}$ & $\mathbf{5 0 \%}$ & $\mathbf{7 5 \%}$ & Mean & STD & Obs. & parameters \\
\hline Sales growth & $1.0 \%$ & $10.6 \%$ & $23.8 \%$ & $17.9 \%$ & $39.6 \%$ & 96,719 & $6.0 \%$ \\
EBITDA margin & $5.8 \%$ & $11.4 \%$ & $18.6 \%$ & $3.7 \%$ & $60.8 \%$ & 96,719 & $12.0 \%$ \\
Sales & 48.2 & 170.2 & 689.2 & 1156.2 & 3176.3 & 96,719 & 100.0 \\
Time-series std of sales growth & $12.7 \%$ & $19.9 \%$ & $33.6 \%$ & $28.2 \%$ & $24.1 \%$ & 96,031 & $20.0 \%$ \\
Time-series std of margin & $2.8 \%$ & $4.7 \%$ & $9.1 \%$ & $13.9 \%$ & $32.6 \%$ & 96,031 & $5.0 \%$ \\
Payout to net income & $20.4 \%$ & $34.8 \%$ & $57.3 \%$ & $41.4 \%$ & $27.1 \%$ & 43,601 & N $(0.5,0.1)$ \\
\hline Depreciation to sales & $2.1 \%$ & $3.6 \%$ & $6.4 \%$ & $6.2 \%$ & $8.7 \%$ & 96,719 & $5.0 \%$ \\
Current assets to sales & $25.6 \%$ & $37.4 \%$ & $58.4 \%$ & $106.1 \%$ & $180.6 \%$ & 96,719 & $35.0 \%$ \\
PPE to sales & $11.4 \%$ & $21.5 \%$ & $46.3 \%$ & $50.3 \%$ & $78.2 \%$ & 96,719 & $20.0 \%$ \\
Current liabilities to sales & $13.8 \%$ & $19.6 \%$ & $29.4 \%$ & $29.6 \%$ & $36.4 \%$ & 96,719 & $20.0 \%$ \\
Equity to sales & $30.3 \%$ & $48.9 \%$ & $86.0 \%$ & $104.4 \%$ & $208.1 \%$ & 96,719 & $40.0 \%$ \\
\hline Market-to-book equity & 0.94 & 1.61 & 2.99 & 2.99 & 4.21 & 96,719 & \\
Return on assets & $0.9 \%$ & $5.1 \%$ & $9.7 \%$ & $3.0 \%$ & $14.8 \%$ & 96,719 & \\
Book return on equity & $2.4 \%$ & $10.7 \%$ & $18.0 \%$ & $7.1 \%$ & $30.1 \%$ & 96,719 & \\
PE-ratio & 4.60 & 11.79 & 21.46 & 17.06 & 51.16 & 96,719 & \\
Leverage & $4.2 \%$ & $19.5 \%$ & $41.6 \%$ & $25.6 \%$ & $23.9 \%$ & 96,719 & \\
\hline
\end{tabular}




\section{Table 2: Estimates for panel vector autoregressions}

This table shows estimates from panel vector autoregressions of equations (1) and (2). Panel A shows the results for the sample from Table 1. We regress sales growth and EBITDA margins on lagged sales and margins using panel vector autoregressions. The data for sales growth and margins is winsorized at the 1\%-level. Standard errors are shown in parentheses. Panel B documents the correlation matrix of the residuals from the panel VAR. Panel $\mathrm{C}$ reports the modeling parameters for long-term sales growth and EBITDA margin used later in the simulation framework.

\begin{tabular}{lcc} 
Panel A: Panel VAR results & & \\
\hline Statistics & $\begin{array}{c}\text { Sales growth } \\
\text { equation }\end{array}$ & Margin equation \\
\hline Sales growth(t-1) & 0.166 & -0.004 \\
& $(0.007)$ & $(0.007)$ \\
Margin(t-1) & -0.166 & 0.596 \\
& $(0.017)$ & $(0.022)$ \\
Obs. & 81,036 & 81,036 \\
\hline
\end{tabular}

Panel B: Residual correlation matrix

\begin{tabular}{lcc}
\hline & Sales growth & Margin \\
\hline Sales growth & 1.000 & \\
Margin & $0.354^{* * *}$ & 1.000 \\
\hline & & \\
Panel C: Long-term sales & growth and margin & \\
\hline & Sales growth & Margin \\
\hline Avg. firm-specific intercepts & 0.070 & 0.049 \\
Avg. long-term rates & $6.0 \%$ & $12.0 \%$ \\
STD of long-term rates & $2.0 \%$ & $1.0 \%$ \\
\hline
\end{tabular}

\section{Table 3: Comparison of simulated values vs. empirical data}

This table shows the differences between the simulated data and the empirical data based on the CRSP-Compustat sample. Differences are constructed by subtracting the corresponding quantiles of the empirical data from the simulated data.

\begin{tabular}{lccccc}
\hline & \multicolumn{5}{c}{ Difference: Simulated - real data } \\
\cline { 2 - 6 } Variable & $\mathbf{1 0 \%}$ & $\mathbf{2 5 \%}$ & $\mathbf{5 0 \%}$ & $\mathbf{7 5 \%}$ & $\mathbf{9 0 \%}$ \\
\hline Sales growth & $-9.13 \%$ & $-8.56 \%$ & $-4.80 \%$ & $-3.84 \%$ & $-16.21 \%$ \\
EBITDA margin & $5.44 \%$ & $2.00 \%$ & $0.65 \%$ & $-2.37 \%$ & $-9.30 \%$ \\
Market-to-book equity & -0.12 & -0.16 & -0.20 & -0.03 & 0.55 \\
Return on assets & $9.16 \%$ & $1.80 \%$ & $2.21 \%$ & $3.29 \%$ & $3.85 \%$ \\
Book return on equity & $17.26 \%$ & $1.50 \%$ & $0.08 \%$ & $1.73 \%$ & $1.26 \%$ \\
PE-ratio & 2.61 & 0.46 & -0.93 & 5.96 & 28.94 \\
\hline
\end{tabular}




\section{Table 4: Implied cost of equity capital methods}

This table summarizes the salient features of the individual implied cost of equity capital methods analyzed in this study. Altogether, we test ten different methods suggested in prior literature. We classify each method according to the model type $(\mathrm{RI}=$ residual income, $\mathrm{AEG}=$ abnormal earnings growth), the level of estimation (firm-level or industry-level), the data input (analyst forecasts or realized values), and the time horizon of the detailed forecast period in years. Column (5) describes the modeling strategy for the terminal value, which is either a perpetuity or a model where values converge before the perpetual growth stage is reached. Column (6) shows the estimates for terminal growth.

\begin{tabular}{|c|c|c|c|c|c|c|}
\hline \multirow[b]{2}{*}{ Method } & \multirow[b]{2}{*}{$\begin{array}{c}\text { Model } \\
\text { (1) }\end{array}$} & \multirow[b]{2}{*}{$\begin{array}{c}\text { Level } \\
(2)\end{array}$} & \multirow[b]{2}{*}{$\begin{array}{c}\text { Input } \\
(3)\end{array}$} & \multirow[b]{2}{*}{$\begin{array}{c}\text { Horizon } \\
\text { (4) }\end{array}$} & \multicolumn{2}{|c|}{ Terminal value modeling } \\
\hline & & & & & $\begin{array}{l}\text { Method } \\
\text { (5) }\end{array}$ & $\begin{array}{c}\text { Growth } \\
(6)\end{array}$ \\
\hline $\begin{array}{l}\text { Claus and Thomas } \\
(2001)\end{array}$ & $\mathrm{RI}$ & Firm & Forecasts & 5 & Perpetuity & $g_{-}$RI $=r f-3 \%$ \\
\hline Gebhardt et al. (2001) & RI & Firm & Forecasts & 3 & $\begin{array}{l}\text { Fading to } 12 ; \\
\text { Perp. after } 12\end{array}$ & $\mathrm{~g}_{-} \mathrm{RI}=0 \%$ \\
\hline $\begin{array}{l}\text { Gode and Mohanram } \\
(2003)\end{array}$ & AEG & Firm & Forecasts & 2 & Perpetuity & $\mathrm{g}_{-} \mathrm{AEG}=\mathrm{rf}-3 \%$ \\
\hline PE ratio & AEG & Firm & Forecasts & 1 & Perpetuity & $\operatorname{AGR}(2)=0$ \\
\hline PEG ratio & AEG & Firm & Forecasts & 2 & Perpetuity & $\begin{array}{l}\operatorname{DIV}(1)=0 \\
\text { g_AEG }=0\end{array}$ \\
\hline MPEG ratio & AEG & Firm & Forecasts & 2 & Perpetuity & $\mathrm{g} \_\mathrm{AEG}=0$ \\
\hline Easton et al. (2002) & RI & Industry & Forecasts & 4 & Perpetuity & $\begin{array}{l}\text { endogenous RI } \\
\text { growth }\end{array}$ \\
\hline Easton (2004) & AEG & Industry & Forecasts & 2 & Perpetuity & $\begin{array}{l}\text { endogenous AE } \\
\text { growth }\end{array}$ \\
\hline $\begin{array}{l}\text { O'Hanlon and Steele } \\
(2000)\end{array}$ & $\mathrm{RI}$ & Industry & Realizations & 0 & Perpetuity & $\begin{array}{l}\text { endogenous RI } \\
\text { growth }\end{array}$ \\
\hline $\begin{array}{l}\text { Easton and Sommers } \\
(2007)\end{array}$ & $\mathrm{RI}$ & Industry & Realizations & 1 realized & Perpetuity & $\begin{array}{l}\text { endogenous RI } \\
\text { growth }\end{array}$ \\
\hline
\end{tabular}



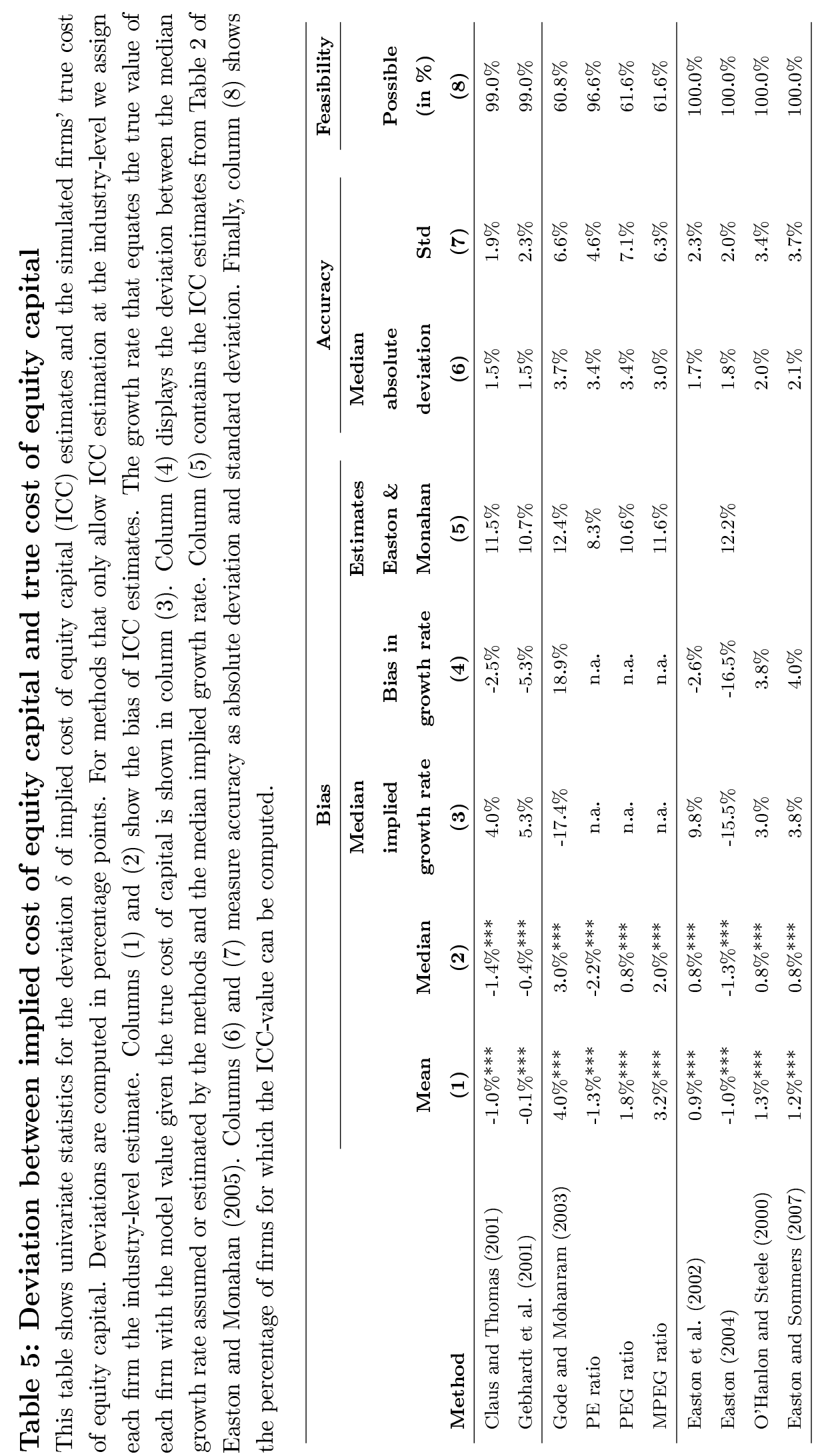


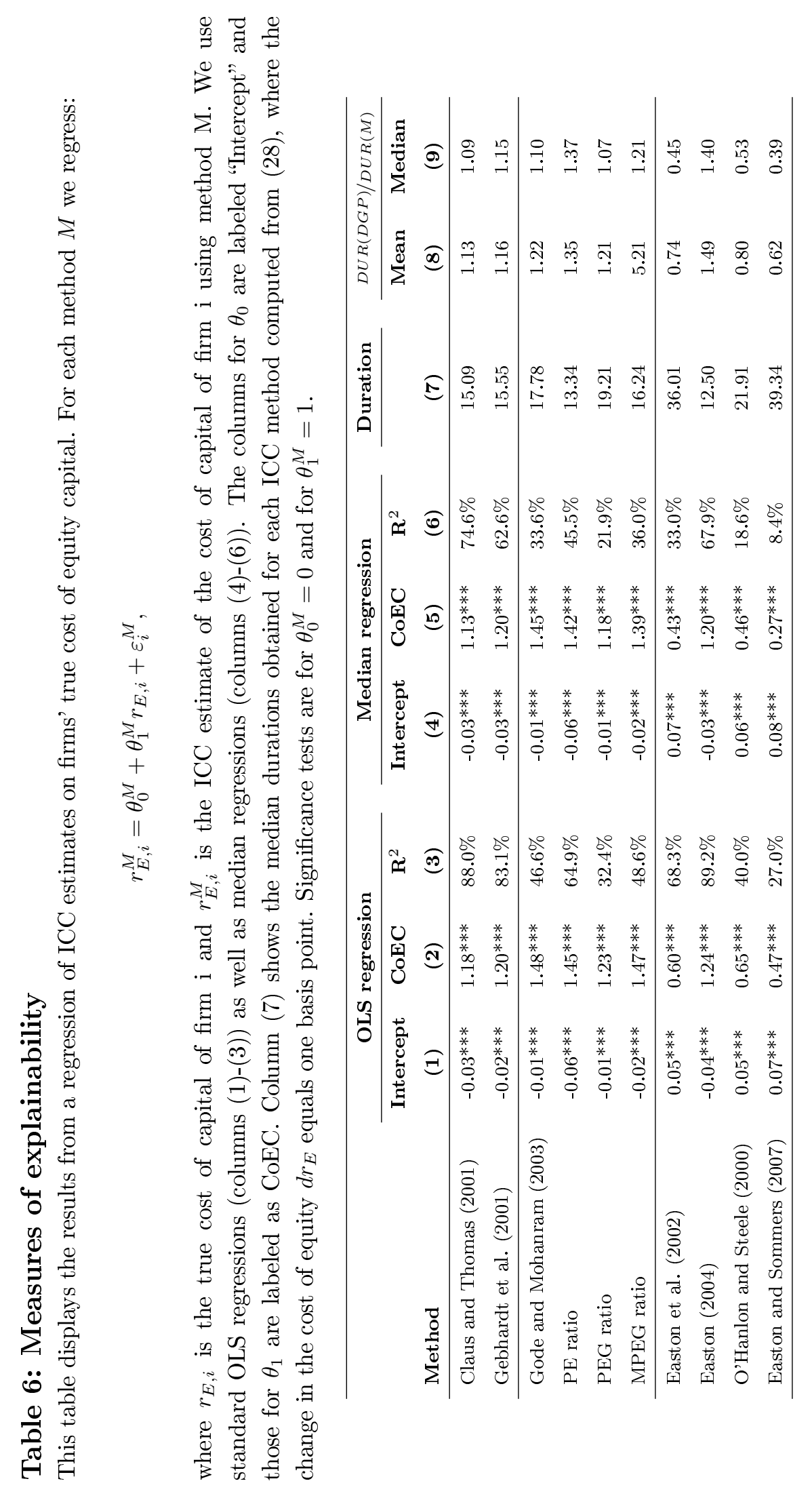




\section{Table 7: Construction of combined implied cost of capital methods}

This table documents the regression analysis for the construction of combined methods, where we estimate the following regression:

$$
r_{E, i}=\theta_{0}+\sum_{M=1}^{M=10} \theta_{M} r_{E, i}^{M}
$$

where $r_{E, i}$ is the true cost of capital of firm i and $r_{E, i}^{M}$ is the ICC estimate of the cost of capital of firm i using method M. Hence, we jointly regress firms' true CoEC on all ten ICC method estimates. In model (1) we conduct an unrestricted OLS regression including an intercept. We apply restricted regressions in models (2) and (3). Model (2) requires coefficients to sum to one and excludes the intercept $\left(\theta=0, \sum_{M=1}^{M=10} \theta_{M}=1\right)$. Model (3) requires in addition that coefficients lie within the unit interval $\left(0 \leq \theta_{M} \leq 1\right)$.

\begin{tabular}{lccc}
\hline & Unrestricted & $\begin{array}{c}\text { No constant, } \\
\text { weights sum to one }\end{array}$ & $\begin{array}{c}\text { No negative } \\
\text { weights }\end{array}$ \\
Specification & $\mathbf{( 1 )}$ & $\mathbf{( 2 )}$ & $\mathbf{( 3 )}$ \\
\hline Intercept & $0.042^{* * *}$ & & \\
Claus and Thomas (2001) & $0.023^{* *}$ & 0.14 & 0.17 \\
Gebhardt et al. (2001) & $0.123^{* * *}$ & 0.24 & 0.26 \\
Gode and Mohanram (2003) & $-0.195^{* * *}$ & -0.13 & 0.00 \\
PE-ratio & $0.165^{* * *}$ & 0.02 & 0.01 \\
PEG ratio & $0.052^{* * *}$ & 0.00 & 0.02 \\
MPEG ratio & $0.269^{* * *}$ & 0.18 & 0.00 \\
Easton et al. (2002) & $-0.149^{* * *}$ & 0.47 & 0.36 \\
Easton (2004) & $0.412^{* * *}$ & 0.18 & 0.18 \\
O'Hanlon and Steele (2000) & $0.013^{* * *}$ & -0.11 & 0.00 \\
Easton and Sommers (2007) & $-0.010^{* * *}$ & 0.01 & 0.00 \\
R-Squared & $95.6 \%$ & & $56.1 \%$ \\
Obs. (in \% of total sample) & $56.1 \%$ & $56.1 \%$ & \\
\hline
\end{tabular}




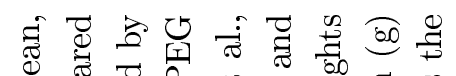

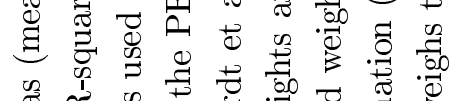

蛋

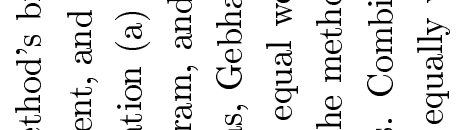

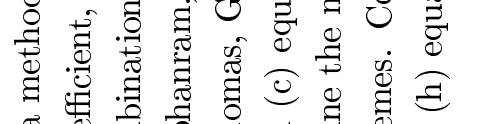

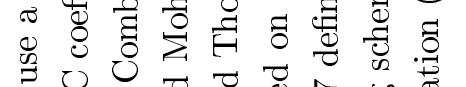

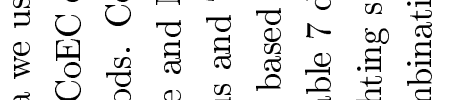

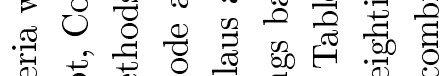

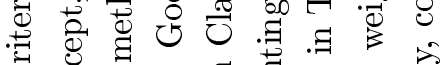

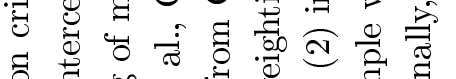

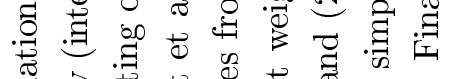

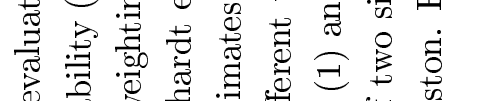

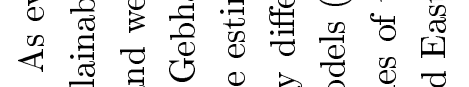

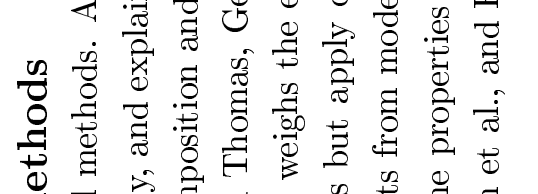

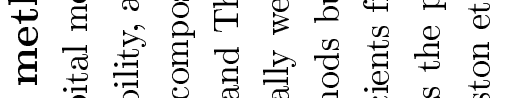

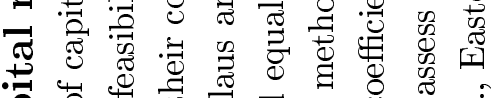

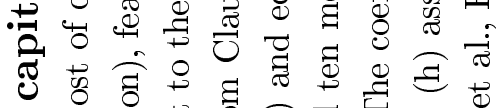

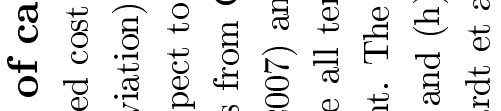

苟

ठ

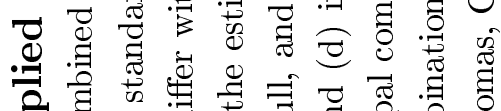

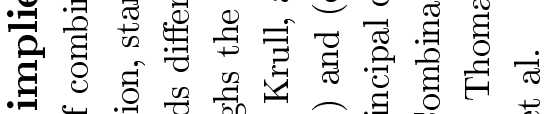

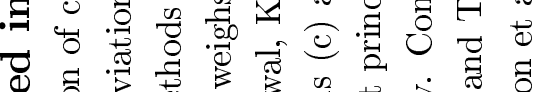

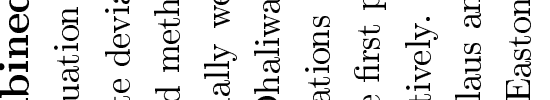

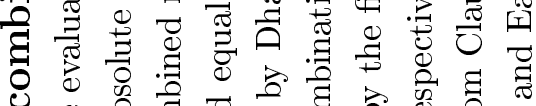

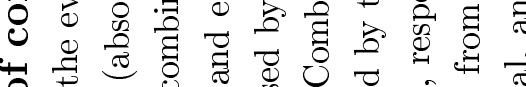

U

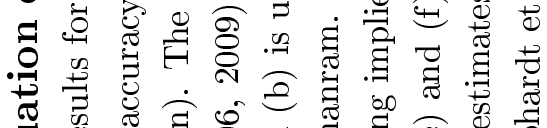

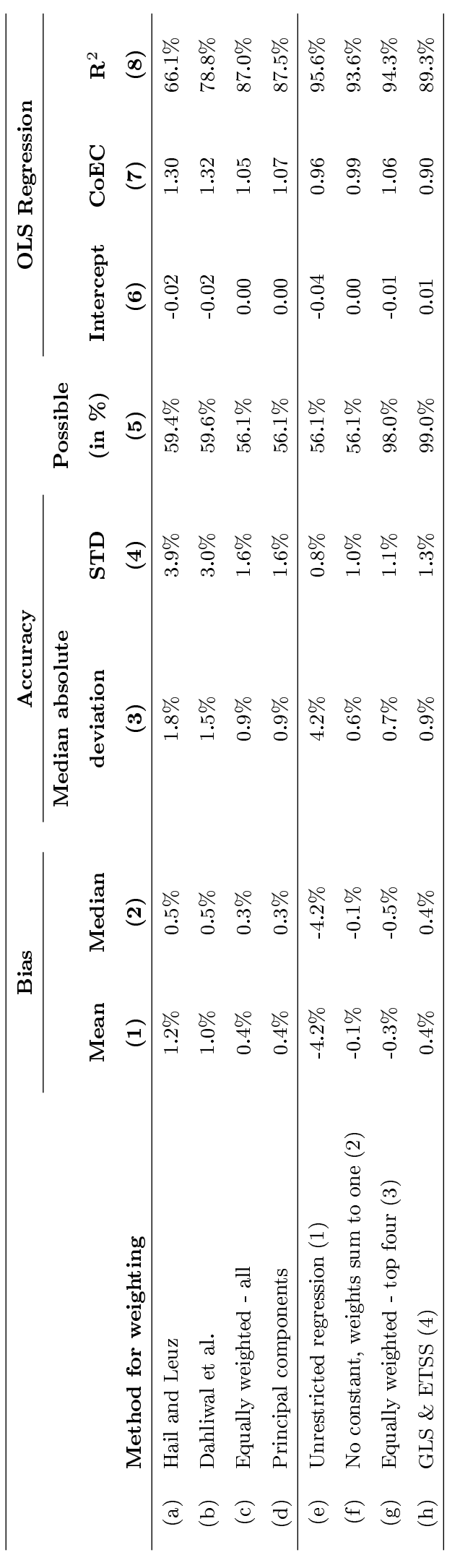

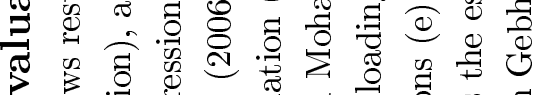

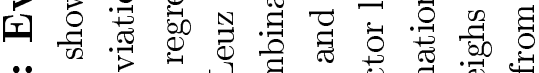

$\ddot{\infty} \frac{0}{0}$ क

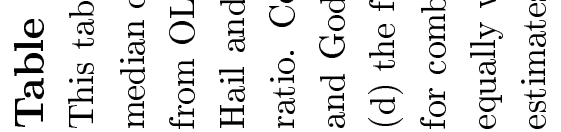




\section{Table 9: Robustness checks}

This table shows the results of several robustness checks, where we assess alternative specifications of our simulated model economy to see how the results are affected by the choice of the underlying model. We repeat results for the baseline model in column (1). The alternative specifications include (2) an adjusted steady-state model, where the equity- and depreciation-to-sales ratio is $50 \%$ and $3.5 \%$ to match the empirical parameters; (3) an analyst forecast bias model, where we assume that earnings forecasts are optimistic such that returns on equity forecasts are biased upward by 3 percentage points for every firm in every forecast period; (4) the use of a dividend discount model instead of a discounted cash flow model. Panel A shows the median values for key financial ratios from Table 3. Panels B to E shows the results for the median bias, standard deviation, the distortion coefficient, and R-squared.

Panel A: Simulated data comparison

\begin{tabular}{|c|c|c|c|c|}
\hline Median accounting item & $\begin{array}{c}\text { Baseline } \\
\text { model } \\
\text { (1) }\end{array}$ & $\begin{array}{l}\text { Adjusted steady- } \\
\text { state model } \\
(2)\end{array}$ & $\begin{array}{c}\text { Analyst } \\
\text { forecast } \\
\text { bias } \\
\text { (3) }\end{array}$ & $\begin{array}{c}\text { Dividend } \\
\text { discount model }\end{array}$ \\
\hline Sales growth & $5.8 \%$ & $5.8 \%$ & $5.8 \%$ & $5.8 \%$ \\
\hline EBITDA margin & $12.0 \%$ & $12.0 \%$ & $12.0 \%$ & $12.0 \%$ \\
\hline Market-to-book equity & 1.42 & 1.57 & 1.42 & 1.25 \\
\hline PE-ratio & 10.86 & 14.09 & 10.86 & 9.37 \\
\hline Duration & 18.91 & 18.70 & 18.91 & 18.63 \\
\hline CoEC (HML) & $10.39 \%$ & $10.57 \%$ & $10.39 \%$ & $9.91 \%$ \\
\hline \multicolumn{5}{|l|}{ Panel B: Median bias } \\
\hline Claus and Thomas (2001) & $-1.0 \%$ & $-2.0 \%$ & $1.7 \%$ & $0.1 \%$ \\
\hline Gebhardt et al. (2001) & $-0.1 \%$ & $-1.5 \%$ & $1.0 \%$ & $0.9 \%$ \\
\hline Gode and Mohanram (2003) & $4.0 \%$ & $1.9 \%$ & $4.6 \%$ & $4.6 \%$ \\
\hline $\mathrm{PE}$ ratio & $-1.3 \%$ & $-2.5 \%$ & $1.3 \%$ & $0.9 \%$ \\
\hline PEG ratio & $1.8 \%$ & $-0.3 \%$ & $1.7 \%$ & $2.2 \%$ \\
\hline MPEG ratio & $3.2 \%$ & $1.1 \%$ & $3.2 \%$ & $3.8 \%$ \\
\hline Easton et al. (2002) & $0.9 \%$ & $0.3 \%$ & $3.4 \%$ & $1.2 \%$ \\
\hline Easton (2004) & $-1.0 \%$ & $-2.1 \%$ & $1.2 \%$ & $0.5 \%$ \\
\hline O'Hanlon and Steele (2000) & $1.3 \%$ & $0.4 \%$ & $1.3 \%$ & $1.3 \%$ \\
\hline Easton and Sommers (2007) & $1.2 \%$ & $0.6 \%$ & $1.2 \%$ & $1.3 \%$ \\
\hline Equally weighted - top four & $-0.3 \%$ & $-1.3 \%$ & $1.8 \%$ & $0.7 \%$ \\
\hline GLS \& ETSS & $0.4 \%$ & $-0.6 \%$ & $2.2 \%$ & $1.1 \%$ \\
\hline
\end{tabular}


Panel C: Method accuracy (standard deviation)

\begin{tabular}{lcccc}
\hline Method & $\mathbf{( 1 )}$ & $\mathbf{( 2 )}$ & $\mathbf{( 3 )}$ & $\mathbf{( 4 )}$ \\
\hline Claus and Thomas (2001) & $1.9 \%$ & $1.0 \%$ & $3.0 \%$ & $2.7 \%$ \\
Gebhardt et al. (2001) & $2.3 \%$ & $1.9 \%$ & $2.9 \%$ & $3.5 \%$ \\
\hline Gode and Mohanram (2003) & $6.6 \%$ & $4.6 \%$ & $6.4 \%$ & $6.3 \%$ \\
PE ratio & $4.6 \%$ & $3.5 \%$ & $5.9 \%$ & $7.9 \%$ \\
PEG ratio & $7.1 \%$ & $5.2 \%$ & $6.1 \%$ & $6.9 \%$ \\
MPEG ratio & $6.3 \%$ & $4.3 \%$ & $2.3 \%$ & $5.9 \%$ \\
\hline Easton et al. (2002) & $2.3 \%$ & $2.6 \%$ & $2.7 \%$ & $2.5 \%$ \\
Easton (2004) & $2.0 \%$ & $1.5 \%$ & $3.4 \%$ & $2.2 \%$ \\
O'Hanlon and Steele (2000) & $3.4 \%$ & $2.8 \%$ & $3.7 \%$ & $3.4 \%$ \\
Easton and Sommers (2007) & $3.7 \%$ & $2.9 \%$ & $1.6 \%$ & $3.7 \%$ \\
\hline Equally weighted - four & $1.1 \%$ & $0.8 \%$ & $1.4 \%$ & $1.3 \%$ \\
GLS \& ETSS & $1.3 \%$ & $1.4 \%$ & & $1.7 \%$ \\
\hline
\end{tabular}

Panel D: Method explainability (CoEC coefficient)

\begin{tabular}{|c|c|c|c|c|}
\hline Claus and Thomas (2001) & 1.18 & 1.05 & 1.55 & 1.37 \\
\hline Gebhardt et al. (2001) & 1.20 & 1.10 & 1.36 & 1.34 \\
\hline Gode and Mohanram (2003) & 1.48 & 1.24 & 1.58 & 1.53 \\
\hline PE ratio & 1.45 & 1.28 & 1.90 & 1.85 \\
\hline PEG ratio & 1.23 & 1.01 & 1.22 & 1.25 \\
\hline MPEG ratio & 1.47 & 1.24 & 1.48 & 1.53 \\
\hline Easton et al. (2002) & 0.60 & 0.45 & 0.58 & 0.44 \\
\hline Easton (2004) & 1.24 & 1.06 & 1.46 & 1.32 \\
\hline O'Hanlon and Steele (2000) & 0.65 & 0.54 & 0.65 & 0.29 \\
\hline Easton and Sommers (2007) & 0.47 & 0.43 & 0.47 & 0.24 \\
\hline Equally weighted - top four & 1.06 & 0.91 & 1.24 & 1.12 \\
\hline GLS \& ETSS & 0.90 & 0.77 & 0.97 & 0.89 \\
\hline
\end{tabular}

Panel E: Method explainability (R-squared)

\begin{tabular}{|c|c|c|c|c|}
\hline Claus and Thomas (2001) & $88.0 \%$ & $94.2 \%$ & $89.1 \%$ & $84.8 \%$ \\
\hline Gebhardt et al. (2001) & $83.1 \%$ & $84.3 \%$ & $81.8 \%$ & $72.4 \%$ \\
\hline Gode and Mohanram (2003) & $46.6 \%$ & $54.4 \%$ & $52.2 \%$ & $51.1 \%$ \\
\hline PE ratio & $64.9 \%$ & $69.4 \%$ & $72.2 \%$ & $51.2 \%$ \\
\hline PEG ratio & $32.4 \%$ & $37.2 \%$ & $33.0 \%$ & $34.9 \%$ \\
\hline MPEG ratio & $48.6 \%$ & $57.4 \%$ & $50.6 \%$ & $54.2 \%$ \\
\hline Easton et al. (2002) & $68.3 \%$ & $61.9 \%$ & $68.0 \%$ & $68.4 \%$ \\
\hline Easton (2004) & $89.2 \%$ & $89.3 \%$ & $89.0 \%$ & $89.4 \%$ \\
\hline O'Hanlon and Steele (2000) & $40.0 \%$ & $51.1 \%$ & $40.0 \%$ & $25.3 \%$ \\
\hline Easton and Sommers (2007) & $27.0 \%$ & $44.7 \%$ & $27.0 \%$ & $15.4 \%$ \\
\hline Equally weighted - top four & $94.3 \%$ & $96.3 \%$ & $93.7 \%$ & $93.4 \%$ \\
\hline GLS \& ETSS & $89.3 \%$ & $89.5 \%$ & $93.7 \%$ & $93.4 \%$ \\
\hline
\end{tabular}

